\title{
DETLEF LIEBS
}

\section{Esoterische römische Rechtsliteratur vor Justinian}




\section{Esoterische römische Rechtsliteratur vor Justinian*}

von Detlef Liebs

Bei Aristoteles unterscheidet man zwischen seinen exoterischen und seinen esoterischen Schriften; die exoterischen waren die veröffentlichten, d. h. die für ein breiteres Publikum bestimmten und daher sorgfältig ausgearbeiteten Werke, während die esoterischen nur dem inneren Gebrauch der Schule dienten, der Aristoteles vorstand, eine Gedächtnisstütze einerseits für den Lehrvortrag, andererseits für weitere Forschungen; sie brauchten für Außenstehende nicht veständlich zu sein, hatten eine mehr oder minder skizzenhafte, jedenfalls gänzlich unprätentiöse Zweckform.

Gewöhnlich stellen wir uns die klassischen Juristenschriften, mehr oder minder bewusst, exoterisch vor. Demgegenüber hat Manfred Fuhrmann, an dessen Formulierungen sich obige vorläufige Begriffsbestimmung anlehnt, ${ }^{1}$ in seiner ersten Miszelle vor 50 Jahren Zur Entstehung des Veroneser Gaius-Textes ${ }^{2}$ am Ende die Vermutung ausgesprochen: „,... vielleicht waren die Institutionen und die Res cottidianae esoterische, nur für den Gebrauch der Schulangehörigen bestimmte Werke, die während einer gewissen Zeit mit der stets sich wandelnden mündlichen Lehre in Übereinstimmung gehalten wurden." Sechs Jahre später kam ich bei den Manualium libri III von Paulus zu einem ähnlichen Ergebnis: Nachschrift eines Lehrvortrags des Spätklassikers. ${ }^{3}$ Okko Behrends vermutete Entsprechendes 1973 beim Enchiridii liber singularis von Pomponius. ${ }^{4}$ David Johnston hat 1987 große Teile des Cervidius Skävola zugeschriebenen Quaestionum publice tractatarum liber singularis verdächtigt, ${ }^{5}$ sich allerdings nicht festgelegt, welche Konsequenzen das für die Entstehung des Werkleins haben würde. Am ausführlichsten hat jüngst Martin Avenarius an Hand des umstrittenen, Ulpian zugeschriebenen Regularum liber singularis die Möglichkeit einer esoterischen Juristenschrift

\footnotetext{
* Erschienen in: Akten des 36. Deutschen Rechtshistorikertages in Halle an der Saale 2006, hg. R. Lieberwirth u. H. Lück, Baden-Baden 2008, S. 40-79.

${ }^{1}$ Manfred Fuhrmann: Nachwort zu Aristoteles, Poetik Griechisch/Deutsch, Stuttgart 1982, S. 144 f.; s. a. Otto Mazal: Geschichte der Buchkultur I: Griechisch-römische Antike, Graz 1999, S. 192.

${ }^{2}$ Manfred Fuhrmann: ZRG RA 73 (1956), S. 341-356

${ }^{3}$ Detlef Liebs: Hermogenians iuris epitomae, Göttingen 1964, S. 48 f.

${ }^{4}$ Okko Behrends: Gnomon 45, S. 793-797, hier S. 796.

${ }^{5}$ David Johnston, On a singular book of Cervidius Scaevola, Berlin 1987.
} 
entfaltet. ${ }^{6}$ Es scheint an der Zeit zu sein, sich grundsätzlich Rechenschaft über esoterische römische Rechtsliteratur zu geben: [S. 41] ihren Anteil am Gesamtbestand der römischen Rechtsliteratur, etwaige Gesetzmäßigkeiten und Strukturen.

Aber nicht alles Paraliterarische gehört hierher, nicht jedes Rechtsgutachten wie die sogenannte Consultatio veteris cuiusdam iurisconsulti, ${ }^{7}$ nicht jede Zusammenstellung von Belegstellen für konkrete Zwecke wie die drei sogenannten Appendices zur Lex Romana Visigothorum ${ }^{8}$ nicht jede Notiz oder Reihe von Notizen am Rande einer Juristenschrift oder einer Gesetzessammlung ${ }^{9}$ und nicht jede aus dem Nachlass herausgegebene Schrift, sondern nur, was, jedenfalls zunächst, lediglich für einen begrenzten Kreis von Rezipienten, eben einen esoterischen Kreis formuliert worden ist, meist ein bestimmter Schülerkreis. Unter esoterischer Rechtsliteratur sollen Texte, sie mögen kurz oder lang sein, verstanden werden, bei denen anzunehmen ist, dass der Autor an sich nicht vorhatte, sie zu veröffentlichen, wenn es auch in seinem Sinn gewesen sein mag, dass sie im Schüler- oder sonst einem geschlossenen Kreis umliefen. Schließlich mögen sie sogar, wenn auch nicht vom Autor, regelrecht publiziert oder sonstwie weiter verbreitet worden sein. Nicht hinzuzurechnen sind dagegen die mannigfachen Publikationen aus dem Nachlass wie Labeos Posteriorum libri, vermutlich von seinem Enkelschüler Proculus (mit Notae) herausgegeben, zumindest neu herausgegeben, oder Cervidius Skävolas Digestorum libri, postum von seinem Schüler Tryphonin mit Notae versehen ediert. ${ }^{10}$ Sie wurden aus schriftlichen Archiven unmittelbar für die Publikation zugerichtet, liefen nicht zunächst in einem engeren Kreis um, sei es auch nur mündlich. ${ }^{11}$

Um einen juristischen Text, bei dem es auf jede Kleinigkeit ankommt, beurteilen zu können, muss man versuchen, so gut wie möglich Klarheit darüber zu gewinnen, unter welchen

\footnotetext{
${ }^{6}$ Martin Avenarius, Der pseudo-ulpianische liber singularis regularum, Göttingen 2005.

${ }^{7}$ Dazu etwa Detlef Liebs: Römische Jurisprudenz in Gallien, Berlin 2002, S. 120 u. S. 138141.

${ }^{8}$ Zur Datierung der ersten beiden schon ins 5. Jh. Liebs: Gallien (wie Anm. 7), S. 141-145; der dritten ins frühe 6. Jh., ebd., S. 181.

${ }^{9}$ Z. B. die Randbermerkungen des Gajus von Antinoë (Papiri della Società Italiana, XI, Nr. 1182), die Scholien der Fragmenta Vaticana (dazu Liebs: Gallien, wie Anm. 7, S. 124-126), die Randsummen der Lex Romana für Burgund (Liebs: Gallien, S. 118 u. S. 265-267) oder die Randsummen der Breviarhandschrift von León (Biblioteca Catedral 15), s. die FaksimileAusgabe von Aureliano Fernandez Guerra y Orbe u. a.: Legis Romanae Wisigothorum fragmenta ex codice palimpsesto Sanctae Legionensis ecclesiae, Madrid 1896, S. 4, 26, 32, 52, 72 usf. bis 330, 332 .

${ }^{10}$ Detlef Liebs: Jurisprudenz, in: Klaus Sallmann (Hg.), Handbuch der lateinischen Literatur der Antike, IV: Die Literatur des Umbruchs von der römischen zur christlichen Literatur 117 bis 284 n. Chr., München 1997, S. 115 f. $=\S 415.6$ W. 6. 7.

${ }^{11}$ Einen Überblick über die mannigfachen Wege zu einer regelrechten Ausgabe gibt Mazal (wie Anm. 1), S. 185-201, speziell zur lateinischen Literatur S. 194 ff.
} 
Umständen er in Worte gefasst wurde. Hat ihn der Autor für eine Ausgabe niedergeschrieben oder diktiert, ${ }^{12}$ so [42] wollte er exoterische Literatur herstellen, ob er die Publikation seines Werkes nun noch erlebt hat oder nicht.= Bei esoterischer Literatur kommt in Betracht, dass der Verfasser den Text lediglich in mündlichem Unterricht formuliert und ein Hörer ihn entweder wörtlich - ganz oder zum Teil - mitstenografiert oder wenigstens ungefähr aufgenommen hat; in beiden Fällen wird er dann, gründlich oder oberflächlich und mehr oder minder verlässlich, redigiert worden sein. ${ }^{13}$ Oft hat der Lehrer auch kurze oder längere Strecken den Schülern diktiert. ${ }^{14}$ Schließlich kam es vor, dass er ihnen seine Aufzeichnungen, die er nur für den Unterricht angefertigt hatte, später überlie $\beta^{15}$ oder dass die Aufzeichnungen aus seiner Feder sonstwie, etwa nach seinem Tod, in Umlauf gerieten.

\section{Zum größeren Teil erhaltene esoterische Schriften}

Betrachten wir zunächst die einigermaßen vollständig oder doch zum größeren Teil erhaltenen esoterischen Juristenschriften. Ich zähle drei: außer den gajanischen Institutionen zwei libri singulares, Werke also, die der Überlieferung nach auf einer einzigen Buchrolle Platz hatten. Der pseudoulpianische Regularum liber singularis ist zu etwa drei Fünfteln erhalten: vor allem die ersten zwei Drittel eines leicht gekürzten Auszugs, und zwar in einer Breviarhandschrift aus der ersten Hälfte des 9. Jh.; ${ }^{16}$ außerdem haben wir drei Fragmente in der Lex

${ }^{12}$ Bei Ulpian tritt Tony Honoré: Ulpian, 2. Aufl., Oxford 2002, S. VIII u. S. 37-75, mit guten Gründen für Diktat ein.

${ }^{13}$ Vgl. zu diesen Möglichkeiten Quintilian, Institutio oratoria, Prooem. § 7. Mitstenografieren oder -schreiben musste nicht notwendig der Schüler selber, der vielmehr auch einen Schreibsklaven mitbringen konnte wie im 6. Jh. n. Chr. der Rechtsstudent Felix von Marseille in Rom seinen Sklaven Andarchius, Gregor von Tours, Hist. 4, 46, s. Liebs: Gallien (wie Anm. 7), S. 67-70. Zur ausgefeilten Technik des Stenografierens für offizielle Protokolle s. Hans C. Teitler: Notarii and exceptores. An inquiry into role and significance of shorthand writers in the imperial and ecclesiastical bureaucracy of the Roman Empire from the early principate to c. 450 A. D., Amsterdam 1985.

${ }^{14}$ Dieter Simon: Aus dem Codexunterricht des Thalelaios, in: ZRG RA 86 (1969), S. 334383, hier S. 335-338 zum Unterricht im oströmischen Reich im 6. Jh.

${ }^{15}$ Wie Galen im 2. und der Geograf Julius Honorius im 4. oder 5. Jh., s. Detlef Liebs: Die Jurisprudenz im spätantiken Italien, Berlin 1987, S. 216 f., auch zu Quintilian (wie Anm. 13); Athenäus, Deipnosophistae 3, 25 = S. 83b; u. Scholion zu Aristophanes, Aves Vers 1242.

${ }^{16}$ Avenarius: Der pseudo-ulpianische liber (wie Anm. 6), S. 16-24. Neuausgabe ohne die bisher üblichen Emendationen im Sinne des klassischen Juristenlateins, ohne kritischen Apparat und mit deutscher Übersetzung von Martin Avenarius: Die pseudo-ulpianische Einzelschrift der Rechtsregeln, Göttingen 2005. 
Dei und zwei in Justinians Digesten. ${ }^{17}$ Und von Paulus wurde die Monografie über die Verwandtschafts- und [43] Schwägerschaftsgrade: De gradibus et adfinibus et nominibus eorum liber singularis, zum größeren Teil in die Digesten aufgenommen. ${ }^{18}$ Eine Handschrift des vollständigen Werks soll noch im 16. Jh. vorhanden gewesen sein, wie ein vir fide dignus dem Humanisten Cujas versicherte; der Mann gab auch an, die Digesten enthielten das Werk fast vollständig (totus fere). ${ }^{19}$ Diese Monografie interessiert hier aber weniger. So eintönig sie, bedingt durch den Inhalt, ausgefallen ist - vielleicht war sie eine frühe Fleißarbeit des späteren Klassikers -, so unterscheidet sich ihr Sprachduktus doch grundsätzlich nicht von dem der Fragmente, die aus den anerkanntermaßen exoterischen Schriften des Paulus erhalten sind.

\section{Gajus, Institutionen}

Der einhellig, wenn auch erst relativ spät überlieferte Titel des gajanischen Werks lautet Institutionum libri IV, wenn Fritz Schulz, Wieacker, Fuhrmann und andere auch behaupten, ursprünglich habe der Titel commentarii gelautet, womit sie meinen: nicht Institutiones. ${ }^{20}$ Dem ist zu widersprechen. Sie stützen ihre Aussage darauf, dass Gajus in diesem Werk auf frühere oder spätere Ausführungen mit den Worten superiore commentario tradidimus, sequenti commentario referemus oder ähnlich verweist. ${ }^{21}$ Dabei steht commentarius aber schlicht für liber, wie denn Tribonian auch an all diesen Stellen, soweit er sie in die Institutionen Justinians übernahm, liber einsetzte. ${ }^{22}$ Wenn Gajus auf ein anderes Werk von sich verwies, sagte er gleichfalls commentariis, nämlich propriis commentariis, womit er einmal [44] einen seiner

${ }^{17}$ Lex Dei 2, 2; 6, 2 = 5, 6 f. des Auszugs; Lex Dei 16, 4 = 26, 1 u. 1a des Auszugs; D. 22, 5, $17=20,6$ des Auszugs; u. D. 44, 7, 25 .

${ }^{18}$ D. 38, 10, 10. Dazu Liebs: Jurisprudenz (wie Anm. 10), S. 164 f. $=\S 423$ W. 48.

${ }^{19}$ Jacques Cujas, Observationes et emendationes 6, 40 (zuerst 1564). Die knapp neun Spalten bei Otto Lenel: Palingenesia iuris civilis, Leipzig 1889, I, Sp. 1103-1111, ergeben aber nur eine knappe Hälfte eines durchschnittlichen liber, der 21 Lenel-Spalten füllte, geht man von den gajanischen Institutionen aus. Aus Ulpians Ediktkommentar sind vom 29. Buch $21 \frac{1}{2}$ Lenel-Spalten erhalten, vom 11. Buch 18, vom 71. Buch 15, vom 32. Buch 13 und vom 35. und 82. Buch je $12 \frac{1}{2}$; vom 17. Buch Ad Sabinum 13 Lenel-Spalten.

${ }^{20}$ Fritz Schulz: Geschichte der römischen Rechtswissenschaft, Weimar 1961, S. 192 f. (engl. Oxford 1946, S. 160); Franz Wieacker: Textstufen klassischer Juristen, Göttingen 1960, S. 187 f.; u. Manfred Fuhrmann: Das systematische Lehrbuch, Göttingen 1960, S. 104 f. Anm. 4. Zutreffend dagegen schon Paul Krüger: Geschichte der Quellen und Litteratur des Römischen Rechts, 2. Aufl., München 1912, S. 203, der meint, Gajus habe sie Institutionum commentarii IV genannt.

${ }^{21}$ Gai. 2,$1 ; 2,23 ; 2,145 ; 2,228 ; 3,17 ; 3,33 ; 3,38 ; 3,81 ; 3,181 ; 3,201 ; 4,77 ; 4,85 ;$ u. 4 , 153.

${ }^{22}$ Inst. 2, 1 pr.; 2, $17 \S 4$ (s. Gai 2, 145); 4, $8 \S 5$ (s. Gai 4, 77); 4, $10 \S 2$ (s. Gai. 4, 85); u. Inst. $4,15 \S 5$ (s. Gai. 4, 153). Dagegen folgt Justinian in der const. Imperatoriam $\S 6$ dem gajanischen Sprachgebrauch. 
Ediktkommentare meinte ${ }^{23}$ und das andere Mal vermutlich seinen ausführlichen Kommentar zu den augusteischen Ehegesetzen, ${ }^{24}$ während er einen seiner Ediktkommentare ein andermal edicti interpretatio und seinen Kommentar zu Quintus Mucius libri quos ex Quinto Mucio fecimus nannte. ${ }^{25}$ Schulz, Wieacker und Fuhrmann war die ältere, schlichtere Bedeutung von commentarius: ,Buch' i. S. v. liber, in welchem Sinn z. B. auch Javolen den Plural gebrauchte, um die von ihm kommentierten Iuris civilis libri von Cassius zu bezeichnen, ${ }^{26}$ nicht geläufig. Ebenso wenig, dass die Bedeutung ,Kommentar’ wesentlich jünger ist als ,Buch’; sie kam erst im 2. Jh. n. Chr. auf ${ }^{27}$ und war erst in der Spätantike allgegenwärtig. ${ }^{28}$

Unabhängig davon halten die meisten derjenigen, die sich mit dem Anfängerlehrbuch des Gajus gründlich beschäftigt haben: Dernburg, ${ }^{29}$ Fritz [45] Schulz, ${ }^{30}$ Wieacker, ${ }^{31}$ Fuhrmann, ${ }^{32}$ Nelson, ${ }^{33}$ Honoré ${ }^{34}$ und ich selber, ${ }^{35}$ das Werk für keine wie üblich vom Autor herausgegebe-

${ }^{23}$ Gai. 3, 33 .

${ }^{24}$ Gai. 3, 54, s. Krüger: Geschichte (wie Anm. 20), S. 203.

${ }^{25}$ Gai. 1, 188 S. 2.

${ }^{26}$ Jav. 2 Cass. D. 35, 1, 54 pr.: in commentariis Gaii scriptum est. Ähnlich GA 91 und GE 9, 1. Auch bei Cicero, De oratore 1, 240: in Sex. Aeli commentariis, und Festus, s.v. Mundus S. 144 L.: refert Cato in commentariis iuris civilis, steht commentariis schlicht für libris; nicht etwa ergibt die Festusstelle, dass Cato in Wahrheit einen Kommentar geschrieben habe, wie Okko Behrends: Der Kommentar in der römischen Rechtsliteratur, in: Jan Assmann u. Burkhard Gladigow (Hg.), Text und Kommentar, München 1995, S. 433 Anm. 26 u. S. 448, vorschnell schloss. Auch die Aufzeichnungen der alten Priesterkollegien hießen libri oder gleichbedeutend commentarii, Francesco Sini: Libri e commentarii nella tradizione documentaria diei grandi collegi sacerdotali romani, in: SDHI 67 (2001), S. 375-415.

${ }^{27}$ Der älteste Beleg findet sich meines Wissens bei Sueton, De grammaticis 18; der nächste bei Festus s.v. Monitores 122 u. 123 L.; und mehrere bei Gellius: 1, 12, 18; 1, 21, 2 u. 4; 2, 24,$5 ; 6,20,1 ; 7,14,5 ;$ u. $18,5,12$.

${ }^{28}$ ThLL III (1901), s.v. commentarius, wo allerdings die Grundbedeutung, schriftliche Aufzeichnung, Buch' zu kurz kommt; dazu Franz Bömer: Der commentarius. Zur Vorgeschichte und literarischen Form der Schriften Caesars, in: Hermes 81 (1953), S. 210-50; Jerzy Linderski: The augural law, ANRW II 16. 3, Berlin 1986, S. 2242-2246; u. Hubert u. Astrid Petersmann, in: Werner Suerbaum (Hg.), Handbuch der lateinischen Literatur der Antike I: Die archaische Lierratur von den Anfängen bis Sullas Tod, München 2002, S. 57 u. 63 f. $=\S 108.1$ u. 5; weniger ergiebig Francesco Sini: Documenti sacerdotali di Roma antica I: Libri e commentarii, Sassari 1983, S. 165 f.

${ }^{29}$ Heinrich Dernburg, Die Institutionen des Gaius - ein Collegienheft aus dem Jahre 161 nach Christi Geburt,Halle 1869.

${ }^{30}$ Schulz: Geschichte (wie Anm. 20), S. 192-199.

${ }^{31}$ Wieacker: Textstufen (wie Anm. 20), S. 186 f.; s. a. ders.: Römische Rechtsgeschichte I, München 1988, S. $131 \mathrm{f}$.

${ }^{32}$ Fuhrmann: Zur Entstehung (wie Anm. 2), S. 355 f.

${ }^{33}$ Hein Leopold Wilhelm Nelson: Die textkritische Bedeutung der ägyptischen Gaiusfragmente, in: Symbolae ... M. David dedicatae, Leiden 1968, I, S. 135-180; u. ders.: Überlieferung, Aufbau und Stil von Gai institutiones, Leiden 1982, S. 74-76.

${ }^{34}$ Tony Honoré, in: TRG 58 (1990), S. 469. 
ne, für die allgemeine und zumal die Fachöffentlichkeit berechnete Publikation wie die anderen klassischen Juristenschriften; zumindest die erste Ausgabe, repräsentiert durch die Florentiner Fragmente, war wohl vielmehr ein zunächst unautorisiert verbreitetes Werk, das später, nach Manthe ${ }^{36}$ nun von Gajus selber, sparsam redigiert und noch einmal verbreitet wurde, der Archetyp der Veroneser Fassung. Aber vermutlich war nicht einmal diese Fassung regelrecht veröffentlicht worden. Immerhin müsste spätestens jetzt der Stoff auf vier Bücher verteilt worden sein, die der Autor unprätentiös commentarii nannte; vielleicht wurde das Werk erst nach seinem Tod regelrecht veröffentlicht. ${ }^{37}$ In Ägypten war allerdings die ältere Ausgabe bis ins späte 5. Jh. verbreitet, möglicherweise neben der neueren.

Gajus, so scheint mir, hat diese sparsame Redaktion nur als vorläufig angesehen und erst einige Zeit später das Ganze durch eine gründliche Überarbeitung und Erweiterung auf sieben Bücher, Res cottidianae genannt, veröffentlicht, ${ }^{38}$ wenn der Erfolg dieser Bearbeitung durch den Autor, die offenbar zu spät kam, auch bescheiden war und ș Verbreitung wie die Institutionen erlangte. 130 Jahre später gelang es auch Hermogenian nicht, die pseudopaulinischen Sentenzen durch seine ehrlicheren und besseren Iuris epitomae zu ersetzen.

Auch die Institutionen des Gajus waren somit eine esoterische Schrift, nicht zur Veröffentlichung bestimmt. Auf die mögliche, wenn auch keineswegs zwingende Folgerung, dass Gajus dann auch nicht für den Titel Institutiones, der hier erstmals in der Rechtsliteratur begegnet, verantwortlich wäre, sondern die, welche das Werk erstmals verbreiteten, sei hier nur hin[46]gewiesen. Da man den Anfängerunterricht im Recht instituere nannte, ${ }^{39}$ lag der Titel auch abgesehen von Quintilian nahe und haben ihn denn auch bald danach viele spätklassische Juristen übernommen: Callistratus, Paulus, Ulpian, Marcian und Florentin.

\footnotetext{
35 Detlef Liebs: Rechtsschulen und Rechtsunterricht im Prinzipat, in: ANRW II 15, Berlin 1976, S. 197-186, hier S. 229-236; s. a. ders.: Jurisprudenz (wie Anm. 10), S. 191 f. $=\S 426$ W. 9. - Zu Renato Quadrato: Le Institutiones nell'insegnamento di Gaio. Omissioni e rinvii, Neapel 1979, s. Karl Hackl, in: ZRG RA 97 (1980), S. 403-410.

${ }^{36}$ Ulrich Manthe: Gaius institutiones. Die Institutionen des Gaius. Herausgegeben, übersetzt und kommentiert, Darmstadt 2004, S. 17 f.

${ }^{37}$ So vorsichtig Wieacker: Textstufen (wie Anm. 20), S. $187 \mathrm{f}$.

${ }^{38}$ Detlef Liebs, Gaius und Pomponius, in: Gaio nel suo tempo. Atti del simposio romanistico, Neapel 1966, S. 63 f.; s. a. ders.: Jurisprudenz (wie Anm. 10), S. 192 f. $=\S 426$ W. 10.

${ }^{39}$ Siehe Pomponius D. 1, 2, 2 § 43 zu Servius u. 47 zu Labeo.
} 


\section{Pseudo-Ulpian, Regularum liber singularis}

Der Regularum liber singularis Pseudo-Ulpians ist wie gesagt hauptsächlich zusammen mit dem westgotischen Römergesetz überliefert, hier in leicht gekürzter Fassung und obendrein um den Anfang und vor allem einen beträchtlichen Teil am Schluss verstümmelt, so dass wir nur mehr etwa drei Fünftel haben, wenn nicht noch weniger. Avenarius datiert den Text in seiner einstigen vollständigen Gestalt in die frühen 180er Jahre, doch sei er damals noch nicht regelrecht veröffentlicht worden, ähnlich wie die gajanischen Institutionen. Es habe sich um ein nicht lange nach Mark Aurels Tod fixiertes Regelwerk der prokulianischen Rechtsschule gehandelt, dessen Grundbestand in dieser Schule schon länger tradiert und unter Commodus um zwischenzeitliche Neuerungen ergänzt worden sei. Erst in epiklassischer Zeit, die Avenarius schon in der Mitte des 3. Jhs. beginnen lässt, sei die bis dahin interne Schulschrift veröffentlicht und als liber singularis geführt worden, obwohl wesentlich umfangrei777cher als ein durchschnittlicher liber. ${ }^{40}$ Dass dieser Text an sich als interne Schulschrift ausformuliert wurde, worauf es in unserem Zusammenhang allein ankommt, überzeugt, wenn der Datierung schon unter Commodus ${ }^{41}$ auch zu widersprechen, vielmehr an Caracalla festzuhalten ist. ${ }^{42}$

Ziehen wir eine kurze Zwischenbilanz. Drei Juristenschriften sind einigermaßen vollständig oder doch zum überwiegenden Teil außerhalb der [47] justinianischen Kompilation erhalten geblieben, der paulinische liber singularis freilich nur nach dem unbekannten Gewährsmann von Cujas. Davon waren zwei esoterische Schriften, Texte aus dem Rechtsunterricht für Anfänger. Der Unterricht also brachte esoterische Schriften hervor: Anfängerunterricht in einer der hauptstädischen Rechtsschulen (Pseudo-Ulpian) und Anfängerunterricht in einer

\footnotetext{
${ }^{40}$ Avenarius: Der pseudo-ulpianische liber (wie Anm. 6), bes. S. 76-85 u. S. 94-148. Nicht alle Argumente sind zwingend.

${ }^{41}$ Avenarius (wie Anm. 6), S. 76 u. Anm. 1, bezieht UR 17, 2: Hodie ex constitutione imperatoris Antonini ... auf Commodus.

42 Siehe schon Detlef Liebs: Ulpiani Regulae - Zwei Pseudepigrafa, in: Gerhard Wirth u. a. (Hg.): Romanitas - Christianitas. Untersuchungen zur Geschichte und Literatur der römischen Kaiserzeit Johannes Straub zum 70. Geburtstag, Berlin 1982, S. 282-292, hier S. 284 u. Anm. 13; u. jetzt, ausführlicher, Hein Leopold Wilhelm Nelson, Gai Institutiones III 182-225, Berlin 2007, S. 101 f., bei aller Indolenz Nelsons gegenüber Pseudepigrafa und ebenso gegenüber römischer Provinzialjurisprudenz, s. S. 97-102, wo er meine Argumente gegen Urheberschaft Ulpians (aaO. S. 283-287) übergeht und Honorés Studien mit einem banalen, nicht stichhaltigen Argument beiseiteschiebt, wie er auch auf S. 98 u. 102 übergeht, dass Ulpian nicht erst 228, sondern schon 223 n. Chr. umkam, Joseph Modrzejewski/Tadeusz Zawadzki: La date de la mort d'Ulpien, in: RH 45 (1967), S. 565-611.
} 
östlichen Provinz (Gajus), wobei einem vor allem die wenige Jahrzehnte später $^{43}$ berühmte Rechtsschule von Beirut in den Sinn kommt.

\section{In Bruchstücken erhaltene esoterische Schriften aus klassischer Zeit}

Aber bemühen wir uns zunächst um weitere Beispiele für esoterische Juristenschriften, auch wenn sie nur mehr in Bruchstücken zu fassen sind oder ihre Natur gar nur Berichten Dritter zu entnehmen ist.

\section{Pomponius, Enchiridii liber singularis}

Dem Bisherigen noch recht nahe steht der Enchiridii liber singularis von Pomponius, denn von ihm haben wir in Justinians Digesten ein sehr langes, offenbar auch ursprünglich zusammenhängendes Fragment, das allein schon ein knappes Drittel eines durchschnittlichen liber füllte. ${ }^{44}$ Aber nicht deshalb interessiert das Werk hier, sondern wegen seines gleichermaßen unliterarischen Karakters. Bei aller Dichte der Informationen ist sein sprachliches Gewand dürftig; und sachlich enthält es zahlreiche Fehler und Ungereimtheiten, die nicht vom Autor stammen können, auch nicht aus einem mündlichen Vortrag in lockerem Kolloquialstil und ebenso wenig aus Skizzen des Lehrers für seinen mündlichen Unterricht; ${ }^{45}$ vielmehr sind diese Mängel am besten durch einen mitschreibenden Schüler zu erklären, der überfordert war. Mit dieser vor allem von Okko Behrends 1973 deutlich ausgesprochenen Annahme ${ }^{46}$ ließe sich auch erklären, dass es neben dem li[48]ber singularis auch Enchiridii libri II von Pomponius gab, ${ }^{47}$ deren wenige erhaltene Fragmente keinen Anhalt bieten, an Herausgabe durch den Autor zu zweifeln. Wie ich vor 30 Jahren zur Diskussion stellte, ${ }^{48}$ könnte Pomponius mit dem ohne seinen Willen verbreiteten liber singularis wie seinerzeit Columella und Quintili-

43 Joseph Modrzejewski: Grégoire le Thaumaturge et le droit romain, in: RH 49 (1971), S. 313-324, bes. S. $315 \mathrm{f}$.

${ }^{44}$ D. 1, 2, 2, um 130 n. Chr. verfasst, s. einerseits $\S 53$, wo das zweite Konsulat des Celsus (129 n. Chr.) erwähnt ist, andererseits $\S 10$, wo die Ediktredaktion von $131 \mathrm{n}$. Chr. noch unbekannt zu sein scheint, und $\S 49$, wonach Hadrian noch lebt. Bei Lenel: Palingenesia (wie Anm. 19), II, Sp. 44-52, füllt das Fragment siebeneinhalb Spalten, was ungefähr 18 FIRASeiten entspricht (einen Vergleichsmaßstab bieten die längeren Fragmente aus Ulpians $D e$ officio proconsulis in der Lex Dei); ein Buch der Institutionen umfasste 40 bis 54 FIRASeiten.

${ }^{45}$ Vgl. oben bei Anm. 12-15.

${ }^{46}$ Oben Anm. 4.

${ }^{47}$ D. Ind. Flor. XI 9. Daraus D. 38, 10, 8 (B. 1); 26, 1, 13; u. 46, 3, 107 (beides B. 2).

${ }^{48}$ Liebs: Rechtsschulen (wie Anm. 35), S. 229 f.; s. a. ders.: Jurisprudenz (wie Anm. 10), S. $146=\S 422 \mathrm{~W} .4$. 
$\mathrm{an}^{49}$ unzufrieden gewesen sein und den Stoff für eine breitere Öffentlichkeit, auf zwei libri verteilt, selber in Worte gefasst haben. Der unautorisiert verbreitete liber singularis braucht bei Annahme eines zunächst esoterischen Texts, der nur unter den Schülern des Pomponius umlief, nicht schon den Titel Enchiridium gehabt zu haben, der offenbar in Anlehnung an das 20 bis 30 Jahre vorher erschienene, in der Sache anspruchsvolle Handbüchlein Epiktets ${ }^{50}$ gebildet wurde. Diese offene Anlehnung ist eher Pomponius selbst zuzutrauen, wenn auch ein hochgemuter Einfall der Schüler denkbar bleibt. Vor allem braucht das Werk nicht nur den Umfang einer einzigen Buchrolle gehabt zu haben, wie Avenarius beim Regularum liber singularis Pseudo-Ulpians gezeigt hat. ${ }^{51}$ Bei einer esoterischen Schrift nötigte nichts dazu, den Text in Bücher aufzuteilen; erst der Zwang, bei Veröffentlichung anzugeben, wie viele Buchrollen die Edition einnahm, hätte - möglicherweise erst geraume Zeit später, als man schon codices hatte und unabhängig vom Umfang eines Normal-liber war - um der Erwartung des liber-Angaben gewöhnten Publikums willen zu der Angabe liber singularis geführt. Auf einer einzigen Buchrolle wäre nach der vorliegenden langen rechtsgeschichtlichen Einleitung für angemessene Ausführungen zum Recht selbst kaum mehr genügend Raum gewesen.

Den Kompilatoren lagen beide Werke vor. Sie exzerpierten beide in der Papiniansmasse nach sechs Schriften von Gajus, fünf Monografien und dem Zwölftafelkommentar, und vor weiteren 13 Monografien hauptsächlich von Paulus, daneben von Ulpian und Arcadius Charisius; ${ }^{52}$ der schönende Index Florentinus verzeichnete folgerichtig nur die libri II. ${ }^{53}$ Wenn die Justinianer trotzdem aus der editorisch schlechteren Schrift verhältnis[49]mäßig viel geschöpft haben, aus der Bearbeitung durch den Autor dagegen nur wenig, so könnte das damit zu erklären sein, dass Pomponius in den von ihm redigierten libri II den rechtsgeschichtlichen Teil, bei dem er mündlich vielleicht allzu lang verweilt war oder den der Schüler besonders ausführlich festgehalten hatte, stark gekürzt oder ganz weggelassen hätte, so wie in der zweiten, knapp redigierten „Ausgabe“ der Institutionen des Gajus, die der Veroneser Handschrift

${ }^{49} \mathrm{Zu}$ Columella s. Liebs: Gaius und Pomponius (wie Anm. 38), S. 63 f.; zu Quintilian, Institutio orat., prooem. $\S 7$, ders.: Italien (wie Anm. 15), S. 216.

${ }^{50}$ Gleichfalls im Singular, während Plinius, Nat. hist., praef. 24; u. Gellius, Noct. Att., praef. 7, den griechischen Buchtitel nur im Plural nennen.

${ }^{51}$ Avenarius: Der paseudo-ulpianische liber (wie Anm. 6), S. 146-148.

${ }^{52}$ Paul Krüger, in: Corpus iuris civilis. Editio stereotypa I, 15. Aufl., Berlin 1928, S. 943; u. Antony Maurice Honoré/Alan Rodger: How the Đdigest Ecommissioners worked, in: ZRG RA 87 (1970), S. 246-314, hier S. 311.

53 Ind. Flor. XI 9, die letzte Angabe zu Pomponius. Vgl. die Angaben IV 1 u. dazu Detlef Liebs, ZRG RA 117 (2000), S. 519.525, hier S. 521 f.; V 1; XI 3 f. u. dazu Liebs: Jurisprudenz (wie Anm. 10), S. $149=\S 422$ W. 12 f.; XX 4 u. dazu ders., ebd. 192 f. $=\S 426$ W. 10; XXIV 7 u. dazu ders., ebd. $209=\S 428.6$ W. 1; u. XXV 10 u. dazu ders., ebd. $172=\S 423$ W. 79. 
zugrundelag, rechtsgeschichtliche Partien wie die Behandlung der archaischen societas ercto non cito weggelassen wurden. ${ }^{54}$

\section{Julian, De ambiguitatibus liber singularis}

Seit Langem irritieren Sprache und Argumentation des De ambiguitatibus liber singularis von Julian, den wir durch den Index Florentinus und mindestens fünf Fragmente der Digesten kennen. ${ }^{55}$ Himmelschein, Fritz Schulz, Wieacker, Guarino und zweifelnd Horak hielten das Werklein für eine nachklassische Arbeit, wenn auch wenigstens zum Teil aus Julian geschöpft. ${ }^{56}$ Seit mehreren Jahrzehnten ist man aber zurückhaltender mit der raschen Annahme solcher nachklassischen Arbeiten oder Bearbeitungen bei jedweder Beanstandung; beweisen lassen sie sich meist nicht. Demgegenüber nehmen Reggi ${ }^{57}$ und zumal Bund, ${ }^{58}$ wie schon im 19. Jh. Buhl, ${ }^{59}$ ein Jugendwerk Julians kautelaren Karakters an, scheinen allerdings von einer Veröffentlichung durch den Autor auszugehen; ebenso Mayer-Maly, der sich uneingeschränkt für Echtheit und auch gegen ein Jugendwerk aus[50] spricht, $^{60}$ worauf Bund wiederum replizierte. $^{61}$ Aber ist bei einer ersten Veröffentlichung eines von Jugend an außergewöhnlich schöpferischen Juristen, dem mit 25 Jahren die endgültige Redaktion des prätorischen Edikts anvertraut und propter insignem doctrinam das Gehalt verdoppelt wurde, ${ }^{62}$ eine literarische

${ }^{54}$ Gai. 3, 154a.

${ }^{55}$ Ind. Flor. I 4 u. D. 28, 6, 41; 32, 62; u. 34, 5, 13. Dieses ist im einschlägigen Digestentitel De rebus dubiis das längste Fragment. Die Kompilatoren haben Fragmente aus ein und demselben liber, die im selben Digestentitel zu stehen kamen, ineinandergeschoben, auch wenn sie ursprünglich nicht zusammenhingen. Das verraten die letzten Bücher der Digesten, wo die redaktionelle Arbeit nur noch flüchtig erledigt wurde und deshalb öfter die Inskription Idem eodem libro stehen blieb, oft von $\mathrm{F}^{2}$ korrigiert. Auch dieses lange Fragment hing offenbar ursprünglich nicht zusammen, zumindest nicht $\S \S 1$ und 2 sowie 5 und 6 , denn $\S \S 2-5$ betreffen Rechtsgeschäfte unter Lebenden, alles andere Testamente.

${ }^{56}$ Jury Himmelschein: Studien zu der antiken Hermeneutica iuris, in: Symbolae Friburgenses in honorem Ottonis Lenel 1931, Leipzig o. J. (wohl 1934), S. 373-424, hier S. 409-417; Schulz: Geschichte (wie Anm. 20), S. 291; Wieacker: Textstufen (wie Anm. 20), S. 175 f. Anm. 248; Antonio Guarino, in: Labeo 12 (1966), S. 394 f.; ders., in: Iura 23 (1972), S. 194198; u. Franz Horak, in: ZRG RA 90 (1973), S. 411-421, hier S. 420 f.

${ }^{57}$ Roberto Reggi, in: Studi Parmensi 2 = 1951 (1952), S. 126.

${ }^{58}$ Elmar Bund: Untersuchungen zur Methode Julians, Köln 1965, S. 86 f.

${ }^{59}$ Heinrich Buhl: Salvius Julianus I, Heidelberg 1886, S. 66 f.

${ }^{60}$ Theo Mayer-Maly, Zu Julians liber singularis de ambiguitatibus, in: Estudios de derecho romano. Homenaje al Profesor Don Carlos Sánchez del Rio y Peguero, Madrid 1967, S. 147150.

${ }^{61}$ Elmar Bund: Salvius Iulianus, Leben und Werk, in: ANRW II 15, Berlin 1976, S. 408-454, hier S. $438 \mathrm{f}$.

${ }^{62} \mathrm{Zu}$ Julians Biografie s. Liebs: Jurisprudenz (wie Anm. 10), S. $101 \mathrm{f} .=\S 413 \mathrm{~A}$; eigens zu seiner Quästur auch Tony Honoré: Law in the crisis of Empire 379-455 AD, Oxford 1998, S. 
Jugendsünde $\mathrm{zu}$ erwarten? Oder muss man weiter hinauf gehen und ein Alter von etwa 20 Jahren wie bei Ciceros De inventione ${ }^{63}$ ansetzen? Die nicht zu leugnenden Mängel betreffen vor allem die gedanklich oft flache Präsentation, die weder Banalitäten noch saloppen Stil scheut, etwa wenn es pauschal heißt: placuit prudentibus, oder: nam ita prudentes hoc inter-

pretati sunt, ${ }^{64}$ oder auch: ... vel, ut propius accedamus, fingamus .... ${ }^{65}$ Das sind auch heute Merkmale ungeschützter mündlicher Rede in vertrautem Kreis, auch von fachlichen Größen jeden Alters. Julian wird diesen Text nicht selbst veröffentlicht haben, der vielmehr - im Wesentlichen wörtlich, wenn auch komprimiert - mitstenografiert worden und dann in Abschriften umgelaufen zu sein scheint. Trifft diese Annahme zu, so hätten wir einen Text aus einem Spezialkurs des Hochklassikers in Kautelarjurisprudenz.

\section{Das sogenannte Fragmentum Dositheanum?}

Der wieder außerjustinianisch zusammenhängend überlieferte Text des Fragmentum Dositheanum, der allerdings lückenhaft ist, war der Beginn eines Anfängerlehrgangs im Stil des gajanischen und des pseudoulpianischen. Er wurde in der Mitte des 2. Jh. verfasst, denn Proculus, Octavenus [51] und, ausführlich, eine Kontroverse zwischen Julian und Neraz sind zitiert, während andererseits die manumissio censu noch in Übung ist. ${ }^{66}$ Die Meinung von Neraz habe auch der Kaiser gebilligt. Auch sonst spielt Kaiserrecht nur eine ergänzende Rolle, so eingangs im Rechtsquellenkatalog. ${ }^{67}$ Wichtiger ist der als kraftvoll geschilderte Prätor; ${ }^{68}$ auch der Prokonsul kommt öfter vor. ${ }^{69}$ Da auch sonst provinziale Bewandtnisse eine nicht

10. Zu den Zweifeln von Antonio Guarino: La formazione dell'editto perpetuo, in: ANRW II 13, Berlin1980, S. 62 ff., s. Nelson: Gai institutiones III 182-225 (wie Anm. 42), S. 95 f.

${ }^{63}$ Martin Schanz: Geschichte der römischen Literatur, I, 4. Aufl. Carl Hosius, München 1927, S. 457 f. $=\S 148$; Wilhelm Kroll: Art. Tullius 29, RE VII A 1, 1939, Sp. 1091-1095; u. Manfred Fuhrmann: Cicero und die römische Republik, München u. Zürich 1989, S. 42 f.

${ }^{64}$ D. $28,6,31$ pr. u. $\S 1$. Eine vergleichbar pauschale Zitierweise findet sich sonst nur noch bei Gajus (inst. 2, 195), in Papinians Definitiones (D. 40, 7, 36), Ulpians Frühschrift De excusationibus liber singularis (Fragm. Vat. 132) und einmal in seinem Kommentar zum Edikt der Ädilen (D. 21, 1, $31 \S 25$ aus Buch 1); die anderen im VIR, IV 1, Sp. 1293 f., angeführten Stellen betreffen nicht eigentlich Literaturzitate.

${ }^{65}$ D. 34, 5, $13 \S 2$ gegen Ende.

${ }^{66} \S \S 10,12$ u. 15. Manumissio censu: $\S 17$, nicht mehr in Übung bei Pseudo-Ulpian (o. unter I. 2.) 1,8 .

${ }^{67} \S \S 1$ f., s. bes. $\S 2$ : Sed edicta imperatoria similiter honorandum, nachdem, jedenfalls in $\S$ 1 , von den Volksgesetzen de Rede war.

${ }^{68}$ Siehe außer $\S 2$, der fortfährt: quod est et praetoris edictum similiter vel proconsulis, vor allem $\S \S 5$ und 12 , auch 8 .

${ }^{69} \S \S 2$ und 8 , hier zweimal. 
geringe Rolle spielen, ${ }^{70}$ liegt die Annahme nahe, der Verfasser sei Reichsjurist aus der Provinz gewesen, wo er vielleicht auch wirkte. Er berichtet auch von zwei Kontroversen unter nicht genannten Juristen, ohne dazu Stellung zu nehmen. ${ }^{71}$

Der Text ist in mehreren griechischen und lateinischen Fassungen überliefert, und zwar als Teil miteinander verwandter Sammlungen von Übersetzungsübungen aus einer Reichssprache in die andere, mit immer wieder denselben Stücken, nur in anderer Reihenfolge und Zusammenstellung. Ursprünglich wird der Text lateinisch gewesen sein, aber keine der überlieferten lateinischen Fassungen ist die ursprüngliche, sondern alle sind das Ergebnis womöglich mehrmaligen Hin- und Herübersetzens. ${ }^{72}$ Da man sich dabei aber um wortwörtliches Übersetzen bemühte, scheint der Gedankengang einigermaßen bewahrt zu sein. Er ist locker gefügt. So heißt es zu Beginn von $\S 3$, „Regulas enim exsequenti mihi ad ea studia necessarium (Böcking ergänzt: visum est) ante omnia scire (Ergänzung Böcking: de condicionibus hominum) - Denn während ich die Rechtssätze darlege, (scheint es mir) für solche Studien nötig, vor allem (über die verschienenen Rechtsstellungen der Menschen) Bescheid zu wissen“; und in $\S 4:$ „Sed ut magis possint singula declarari, melius videtur incipere a libertis adferre et primum de Latinis scribere, ne saepius eadem interpretari cogamur - Aber damit die Einzelheiten deutlicher erklärt werden können, ist es offenbar besser, zunächst (Kenntnisse) von den Freigelassenen zusammenzutragen und als erstes etwas über die Latiner niederzuschreiben, damit wir nicht gezwungen sind, mehrmals dasselbe zu erläutern.“ In $\S 5$ heißt es dramatisierend: ,... et manumissores ausi erant ... per vim ... Interveniebat praetor et non patiebatur ... - und die Freilasser wagten es, gewaltsam ... Da schritt [52] der Prätor ein und duldete nicht, ..." All das deutet auch hier auf einen Text, den der Autor sich zwar irgendwie schriftlich vorstellte (s. § 4 primum de Latinis scribere), aber doch wohl lediglich als Niederschrift durch die Hörer, jedenfalls kaum regulär veröffentlicht, wenn hier auch Unsicherheit zurückbleibt.

Am ehesten war der Verfasser einer der vielen kleinen Rechtslehrer außerhalb der beiden großen Rechtsschulen in Rom, ${ }^{73}$ der nicht literarisch hervortreten wollte. Jedenfalls ist es

\footnotetext{
${ }^{70} \S \S 12$ u. 17 am Ende.

$71 \S \S 1$ u. 17.

72 Näher zu diesem Text Liebs: Jurisprudenz (wie Anm. 10), S. $207=\S 428.4$; zur neuen Ausgabe der prominentesten dieser Sammlungen von Giuseppe Flammini, München, Leipzig 2004, s. Detlef Liebs, in: ZRG RA 124 (2007), S. 473-476.

${ }^{73} \mathrm{Zu}$ ihnen Detlef Liebs: Rechtskunde im römischen Kaiserreich, in: Martin J. Schermaier u. a. (Hg.): Iurisprudentia universalis. FS Theo Mayer-Maly zum 70. Geburtstag, Köln 2002, S. 383-407; zum 2. Jh. auch S. 387 f. u. S. 399 f. Vgl. Petronius, Satyricon 46, 7, was nicht bloß einen Autodidakten bezeugt, wie Wolfgang Kunkel: Herkunft und soziale Stellung der röm.
} 
kaum angebracht, zu versuchen, ihn mit einem der bekannten großen Juristen zu identifizieren, etwa mit Gajus. $^{74}$

\section{Skävola, Quaestionum publice tractatarum liber singularis}

Von den Quaestiones publice tractatae haben wir neun, kleine und größere, Digestenfragmente, knapp drei Spalten in Lenels Palingenesie, ein gutes Zehntel eines durchschnittlichen liber. ${ }^{75}$ So, wie die Stücke überliefert sind, können sie nicht von dem spätklassischen Juristen Cervidius Skävola, dem Lehrer Papinians, Tryphonins und des Paulus, stammen, ${ }^{76}$ obwohl der Index Florentinus und die Mehrzahl der Digestenfragmente - nicht alle - die Schrift ihm zuschreiben. ${ }^{77}$ Aber statt unbekannte nachklassische Bearbeiter zu bemühen, die in der Spätantike cervidisches Material verunstaltet hätten, [53] an ihren intellektuellen und sprachlichen Defiziten $^{78}$ aber zu erkennen seien, ist ein eigener Autor wahrscheinlicher, ${ }^{79}$ allerdings eher ein Zeitgenosse des Spätklassikers, vielleicht sogar etwas älter als dieser, jedenfalls ein unberühmter. Er kann sich trotzdem mit dem Cognomen der berühmtesten Juristensippe geschmückt haben, nicht anders als Cervidius selbst; denn dieser gebürtige Africaner war offenbar bescheidener Herkunft, hat das Cognomen schwerlich geerbt, sondern sich erst im Verlauf oder zur Vorbereitung seiner beruflichen Erfolge zugelegt oder zulegen lassen. ${ }^{80}$

Juristen, Weimar 1952, S. 344 Anm. 27, meinte, denn dafür dürfte der Knabe, um den es geht, zu klein gewesen sein; ferner Ulpian, De excusationibus liber singularis, Frg. Vat. 150; Mod. 2 exc. D. 27, 1, 6 § 12; CIL, X, Nr. 8387 u. dazu Liebs, ebd., S. 387; u. CIL, VIII, Nr. 12418 = ILS, Nr. 7748 u. dazu Detlef Liebs: Römische Jurisprudenz in Africa, 2. Aufl., Berlin 2005, S. $26 \mathrm{f}$.

${ }^{74}$ So Heinrich Eduard Dirksen: Die römisch-rechtlichen Quellen des Magister Dositheus, in: ders.: Hinterlassene Schriften; II, Leipzig 1871, S. 392-411 (zuerst 1857); u. Antony Maurice Honoré, in: RIDA 12 (1965), S. 301-23. Weitere Vermutungen bei Krüger: Geschichte (wie Anm. 20), S. 286 Anm. 60.

${ }^{75}$ Johnston (wieAnm. 5), S. 81 u. Anm. 2.

${ }^{76}$ Gerhard Beseler: Miscellanea, in: ZRG RA 44 (1924), S. 359-395, hier S. 359 f.; Schulz: Geschichte (wie Anm. 20), S. 295; u. zumal Johnston (wieAnm. 5), mit den Rez. von Wolfgang Waldstein, in: Gnomon 61 (1989), S. 750-752; u. Tony Honoré, in: ZRG RA 107 (1990), S. 620-622.

${ }^{77}$ Ind. Flor. XVIII 6. Die Kompilatoren der Digesten nennen den Autor zwar gleichermaßen Scaevola, zögern aber mehrmals, ihn mit Cervidius Scaevola gleichzusetzen, s. D. 35, 2, 9496; u. 36, 1, 77-82.

${ }^{78}$ Zur Sprache des Werkleins Johnston (wieAnm. 5), S. 87-91, der den Erkennungsdienst, den der individuelle Sprachstil leisten kann, jedoch wohl unterschätzt.

${ }^{79}$ So auch Honoré (wie Anm. 76), S. 621 unten.

${ }^{80}$ Liebs: Jurisprudenz (wie Anm. 10), S. $114=\S 415.6$ A. 
Johnston und Honoré meinen, die Quaestiones publice tractatae bzw. die angenommene tiefgreifende Bearbeitung sei in der Spätantike anzusetzen: gegen $300 \mathrm{n}$. Chr. ${ }^{81}$ bzw. im 4./5. $\mathrm{Jh}^{82}$ Das ist schon wegen der Zitate weniger wahrscheinlich. Julian wird mit Worten angeführt, als lebe er noch: „Hoc autem, quod sentimus, Iulianus quoque in libris suis probatUnd das, was wir meinen, billigt auch Julian in seinen Büchern““. ${ }^{83}$ Außerdem sind Sabinus und Proculus mit einer Streitfrage zitiert, in der kurz für Sabinus Partei ergriffen ist; ferner findet sich ein unbestimmtes respondetur. ${ }^{84}$ An drei weiteren Stellen wurde offenbar stillschweigend Julian benutzt und an noch einmal vieren vermutlich; einmal wahrscheinlich auch Neraz. ${ }^{85}$ Vor allem wird kein einziges Mal der Kaiser auch nur erwähnt und schon gar nicht als rechtliche Autorität angeführt. Auch inhaltlich ist nirgendwo spätantiker Rechtszustand auszumachen. Der Formularprozess ist noch wie selbstverständlich vorausgesetzt, wenn der Autor auch keine klare Anschauung hat, wie sich das praktisch auswirkte. ${ }^{86}$ Und beim Verwertungsrecht des Pfandgläubigers steht der Text noch auf dem älteren Standpunkt von Sabinus, Cassius, Javolen, Pomponius, Gajus und wohl auch noch Cervidius Skävola, wonach das Verwertungsrecht des Pfandgläubigers eigens [54] vereinbart sein musste. ${ }^{87}$ Ulpian dagegen stellte 216 n. Chr. fest: ,sed etsi non convenerit de distrahendo pignore, hoc tamen iure utimur, ut liceat distrahere, si modo non convenit, ne liceat - Aber auch wenn keine Vereinbarung über die Verwertung des Pfandes getroffen worden ist, gehen wir doch von Rechts wegen davon aus, dass die Verwertung erlaubt ist, wenn nur nicht vereinbart worden ist, dass sie nicht erlaubt sei.“ ${ }^{68}$ Die Paulussentenzen fordern, wenn nichts vereinbart ist, dreimalige An-

${ }^{81}$ So Johnston (wieAnm. 5), S. 94-96 für die von ihm angenommene Bearbeitung.

${ }^{82}$ So Honoré (wie Anm. 76), S. $621 \mathrm{f}$. für das von ihm angenommene eigene Werk.

${ }^{83}$ D. 28, 6, 48 § 1 a. E. Dazu Johnston (wieAnm. 5), S. 82 f., aber auch Tomasz Giaro, in: RJ 8 (1989), S. 54 f. Das Misstrauen von Honoré gegenüber diesem Zitat, s. ders. (wie Anm. 76), S. 622 oben und unten: „slender assumption“, scheint mir nicht berechtigt zu sein.

${ }^{84}$ D. 28, 6, 48 § 1 gegen Anfang. Streitfrage: D. 46, 3, $93 \S 3$.

${ }^{85}$ Johnston (wieAnm. 5), S. 83. Die lediglich stilistischen Parallelen, die Honoré (wie Anm. 76), S. 621 f., ausmacht und die hauptsächlich zu Spätklassikern führen, scheinen mir dagegen weniger signifikant zu sein.

${ }^{86}$ D. 46, 3, 93 pr. u. dazu Johnston (wieAnm. 5), S. 65 ff., vor allem 68. D. 44, 3, 14 betrifft das interdictum utrubi, Johnston, ebd., S. $60 \mathrm{f}$.

${ }^{87}$ D. 44, 3, $14 \S 5$ et convenerit ... vendere. Vgl. Javolen 15 Cass. D. 47, 2, 74; Pomponius 35 Sab. D. 13, 7, 8 § 3 zur fiducia; Gai. 2, 64; u. Cerv. Scaev. 6 resp. D. 46, 1, 63. Dazu Johnston (wie Anm. 5), S. 64 f.; unbefriedigend Max Kaser: Studien zum römischen Pfandrecht, Neapel 1982, S. 21 f. (zuerst 1975) u. S. 74 f. (zuerst 1976).

${ }^{88}$ Ulp. 41 Sab.: De furtis, D. 13, 7, 4. Die Stelle endet mit der Feststellung, eine Verwertung ungeachtet dessen sei furtum, fährt jedoch fort nisi ei ter fuerit denuntiatum ut solvat et cessaverit, eine typisch justinianische teilweise Rücknahme der vorigen Aussage, vgl. etwa D. 5, 3, $20 \S 11 ; 12,4,3 \S \S 2$ u. $3 ; 12,4,5$ pr. u. $\S 1 ; 22,3,25 \S 4 ; 39,5,25 ; 40,8,9 ;$ u. $48,10,15 \S$ 6. 
drohung der Verwertung, ${ }^{89}$ was auch schon Ulpian nach dem seinerzeit geltenden Recht verlangt haben kann. Mit dem bei nicht vorgesehener Verwertung zu beobachtenden Verfahren befasste sich Ulpian in der genannten Stelle nicht; hier ging es ihm nur darum, ob der eigenmächtig verwertende Pfandgläubiger furtum begeht.

Verzichtet man also auf die Einführung von Unbekannten, die in der Spät-antike an klassische Texte Hand gelegt und sie verdorben haben sollen, und macht man sich von der Vorstellung frei, schwache und fehlerhafte Ausführungen seien immer erst in nachklassischer Zeit niedergeschrieben worden, ${ }^{90}$ gespeist von der bekannten allgemeinen Niedergangstheorie, so eröffnet sich die Möglichkeit, in den erhaltenen Fragmenten die Reste eines eigenen Werks zu fassen, das von einem sonst unbekannten Autor geschaffen wurde, einem Zeitgenossen Julians oder wenig jünger. Als Entstehungsort liegt dann Rom, jedenfalls Italien am nächsten. Der Werktitel, welcher an die klassischen Quästionenwerke anknüpft, ${ }^{91}$ aber auch Diktion und Inhalt sprechen für ein Produkt aus Rechtsunterricht, wobei die Rechtsschule in Rom bzw. eine der beiden bekannten wohl weniger in Betracht kommt. Vielleicht konnte dort aber auch jemand unterrichten, der den selbst aufge[55]worfenen Rechtsfragen öfter nicht gewachsen war. ${ }^{92}$ Andererseits dürfen wir, wie schon am Fragmentum Dositheanum zu beobachten war, nicht davon ausgehen, dass die großen Rechtsschulen in Rom ein Monopol gehabt hätten. Neben dem anspruchsvollen Unterricht dort muss es, auch nach den Inschriften zu urteilen, jedenfalls seit dem 2. Jh. in Italien und in den Provinzen mannigfachen Privatunterricht gegeben haben, angeboten von kleinen Rechtslehrern, wo immer es ihnen beliebte, vor allem hinreichend einträglich war. ${ }^{93}$

Mit Verortung im Rechtsunterricht kommt auch gut überein, wenn unser Autor freimütig mitteilt: „Nos didicimus ... - Wir haben gelernt ..." ${ }^{\text {994 }}$ oder „Plus ego ... accepi ... - Darüber

${ }^{89}$ PS 5, 2, 1 aus dem Breviar.

${ }^{90}$ Das kritisierte schon Giaro (wie Anm. 83), S. 55 ff., insoweit zu Recht; im Übrigen theoretisiert er allzu abstrakt, ohne breitere Kenntnis der unbestrittenen Schriften von Cervidius Skävola, denen Johnston seine Maßstäbe entnommen hat, um zu beurteilen, was dieser geschrieben haben kann und was nicht.

${ }^{91}$ Etwa von Fufidius, zitiert von African D. 43, 2, 5; Celsus filius, zitiert von Ulpian= D. 12, 1, $1 \S 1 ; 28,5,9 \S 2 ;$ u. 34, 2, $19 \S 3$; oder von African. Ulpian sollte Publicae disputationes veröffentlichen, den vollständigen Titel überliefert Arcadius Charisius bei Diokletian CJ 9, 41, 11. Unergiebig insoweit Johnston (wieAnm. 5), S. 84 f.

92 Johnston (wieAnm. 5), S. 15-78, zusammenfassend S. 80-82; u. Honoré (wie Anm. 76), S. 620 f., bes. zu D. $28,6,48 \S 1$ u. $36,1,81$.

${ }^{93}$ Nachweise oben Anm. 73.

${ }^{94}$ D. 28, 6, 48 § 1 nach Mitte. Vgl. Ego didici aus den angeblich paulinischen Manualia (dazu sofort), Frgm. Vat. 50; und das zurückhaltendere Hoc et ego verius esse didici bei Paul. 9 ed. D. 3, 5, 14 sowie dasselbe mit verum vermutlich aus Paul. 8 Plaut., Fragmentum de formula 
hinaus habe ich ... mitbekommen ... “95 Breite Ausführungen $\mathrm{zu}$ den accessiones possessionum ${ }^{96}$ ein sehr theoretischer Gegenstand, beginnen mit dem wohlfeilen Eingeständnis: „,.. nihil in perpetuum neque generaliter definire possumus - dazu kann man nichts ewig Gültiges und nichts allgemein bestimmen.“ Nach kurzer Mitteilung eines Rechtssatzes fährt unser Mann mit der rhetorischen Frage fort: „Quo bonum est hoc dicere? - Wofür ist es gut, das zu sagen?“, um nach einer knappen Begründung noch einmal zu versichern „Atquin magna est huius rei differentia; nam ... - Indessen gibt es bei dieser Sache einen großen Unterschied; denn ...“; ; ${ }^{97}$ oder er sagt: ,... creditur et nos dicimus semper praevalere ... - ... wie man annimmt, und wír sagen dass ... immer vorgehe. ${ }^{، 98}$ Ein Fall beginnt mit der, nähme man sie wörtlich, unsinnigen Konstellation: „Wenn ein Vater, nachdem er den Sohn enterbt hat, einen Fremden substituiert hat, ... - Si pater exheredato filio substituit heredem extraneum, ... “99

[56] Offenbar handelte es sich um einen Unterricht für Fortgeschrittene, wo schwierige Rechtsfragen aufgeworfen wurden, wie wir es aus den Quästionenwerken der Klassiker kennen. ${ }^{100}$ Aber welch ein Unterschied! Dieser Lehrer konnte zwar durchaus auch mit Kenntnissen aufwarten, ${ }^{101}$ aber seine Erörterungen überzeugen in der Sache allzu oft in keiner Weise. Anstatt triftige oder wenigstens einschlägige Argumente gegeneinander abzuwägen, ringt er sichtlich mit den selbst gestellten Rechtsfragen, dringt oft nicht zum Kern des Problems vor, sondern klammert sich an Äußerlichkeiten. Ein Diskurs, der für Sachgesichtspunkte offen gewesen wäre, findet nicht statt; vielmehr verläuft die Argumentation eingleisig und ist der Autor schon zufrieden, wenn er einen Gedanken zu Ende zu führen vermochte, wobei er sich

Fabiana $\S 2$ a. E., beides von Wieacker: Textstufen (wie Anm. 20), S. 275 nach anderen kurz einem Bearbeiter zugeschrieben.

${ }^{95}$ D. $32,103 \S 1$. In dieser Bedeutung begegnet accepi außerdem einmal bei Celsus D. 30, 20 : et a patre sic accepi; zweimal bei Callistratus D. 4, 6, 4: dolum malum eo pertinere accepi; $\mathrm{u}$. 50, 6, 6 § 13: compellendos subire publica munera accepi; und ähnlich unprätentiös viermal bei Paulus, s. VIR, I, Sp. 94 Z. 26-32; s. a. Venulejus D. 45, 1, 137 pr. si (sc. promittens) post interrogationem aliud acceperit. Daraus mit Honoré (wie Anm. 76), S. 622, auf eine besondere Nähe unseres Autors zu den Spätklassikern zu schließen, erscheint jedoch allzu gewagt.

${ }^{96}$ D. 44, 3, 14 pr. Der Beginn des Fragments veranlasste die Kompilatoren offenbar zur Ergänzung der Rubrik von D. 44, 3 um et de accessionibus possessionum.

${ }_{97}$ D. 46. 3. 93 pr.

${ }^{98}$ D. $46,7,21$.

${ }^{99}$ D. 32,103 pr.

${ }^{100}$ Insoweit zutr. Giaro (wie Anm. 83), S. 53 f., gegen Johnston (wie Anm. 5), S. 11-13 u. 84 f.

${ }^{101}$ Vgl. zu D. 28, 6, 48 § 1 etwa Ulp. 4 Sab. D. 28, 6, 10 § 7; oder zu D. 46, 3, 93 pr. wiederum Ulp. 46 Sab. D. 19, 1, 10 u. 46, 1, 5 sowie Ven. 3 stip. D. 45, 2, 13. 
mit den juristischen Größen durchaus messen will. Aufgelockert wird das Ganze durch persönliche Bekenntnisse über Erlerntes und Gewissheiten oder auch Banalitäten. ${ }^{102}$

All das legt den Schluss nahe, dass wir es auch hier mit Aufzeichnungen eines Hörers zu tun haben, der hier an öffentlichem Rechtsunterricht für Fortgeschrittene teilnahm. Der Unterricht hatte allerdings ein bescheidenes Niveau, jedenfalls nicht das des Cervidius Skävola, dem der Text wie gesagt auch nur von einem Teil der Überlieferung zugeschrieben wird. Trotzdem ist es ungerecht, wenn jetzt Volljuristen ihn studieren und beurteilen; so viel hatte der Autor nicht verantworten wollen.

\section{Paulus, Manualium libri III}

Von dieser Schrift ist schon der Titel bemerkenswert, eine Lehnübersetzung des im Griechischen beliebten Titels 'E $\chi \chi \varepsilon 1 \rho i ́ \delta 1 \alpha,{ }^{103}$ den Pomponius oder schon seine Schüler noch lediglich transliteriert hatten (s. oben 1.). Die [57] Schrift hatte einen Umfang von drei libri. ${ }^{104}$ Der im Griechischen als Buchtitel üblichere Plural ${ }^{105}$ ist beibehalten. Andere Werke mit dem Titel Manuale oder Manualia sind nicht bezeugt. ${ }^{106}$ Deshalb ist bei der Deutung des Buchtitels von den sonst erreichbaren Quellen auszugehen, und das sind ein griechisch-lateinisches und ein

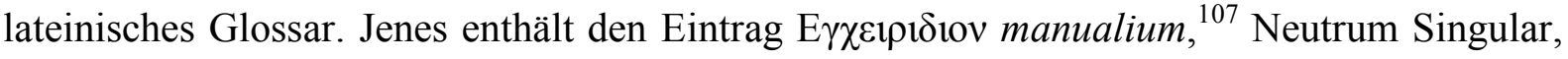
eine alternative Form zu manuale. Und dieses: Manuale liber ad gerendum aptus qui enchiridion dicitur. ${ }^{108}$ Wenn dieses Glossar auch erst nachisidorisch, jedoch immerhin frühmittelalterlich ist, ${ }^{109}$ so stammt der Inhalt doch regelmäßig noch aus der Spätantike, weshalb wir die-

${ }^{102}$ D. 28, 6, 48 § 1 nos didicimus ... praevalere libertatem; D. 42, 8, 24 ius civile vigilantibus scriptum est; D. 44, 3, 14 pr. De accessionibus possessionum nihil in perpetuum neque generaliter definire possumus; consistunt enim in sola aequitate; u. D. 46, 7, 21 nos dicimus semper praevalere rei iudicatae clausulam.

${ }^{103}$ Plinius d. Ä., Nat. hist., praef. 24; u. Gellius, Noct. Att., praef. 7. Vgl. Glossae graecolatinae udSt., Georg Goetz (Hg.): Corpus glossariorum Latinorum II, Leipzig 1888, S. 285, Z. 20, wo als Übersetzung des Singular Manualium (Neutrum Singular) angegeben ist.

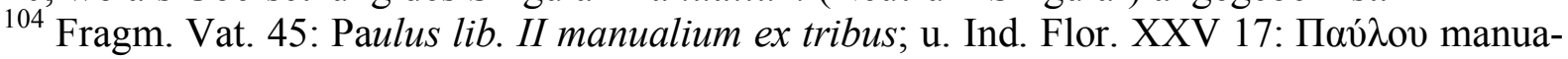

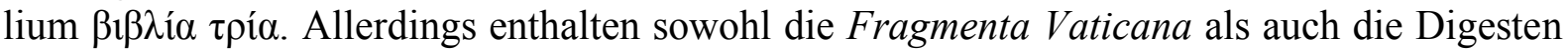
nur Fragmente aus Buch 1 und 2, die Digesten aus beiden Büchern etwa gleich viel.

${ }_{105}$ Oben Anm. 103. Epiktet, an den sich Pomponius hielt, bevorzugte allerdings den Singular.

106 ThLL VIII, Sp. 335, Z. 2-6 udSt. manuale unter 1. (1938).

107 Goetz: Corpus II (wie Anm. 103), S. 285, Z. 20.

108 Georg Goetz (Hg.): Corpus glossariorum Latinorum V, Leipzig 1894, S. 605, Z. 6

${ }^{109}$ Goetz: Corpus V (soeben Anm. 108), S. XXXII-XXXIV. 
se Aussagen ebenso wenig wie das Beispiel des Pomponius mit Peter Stein ${ }^{110}$ beiseiteschie-

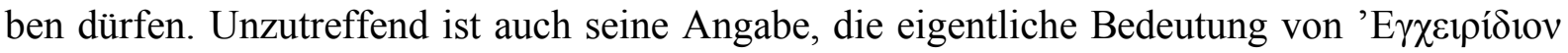
sei ,Dolch' oder ,Messer'; ${ }^{11}$ vielmehr bedeutet das Wort, wie seine Herkunft ergibt, allgemein ,was man in der Hand hat oder hält', und derlei Dinge gibt es mehrere, darunter gewiss, zumal in älterer Zeit, auch den Dolch, aber ebenso, wenn auch erst in jüngerer Zeit, das Handoder Taschenbuch. ${ }^{112}$ Beim Buchtitel Manualia stand der pomponische Titel Enchiridium offensichtlich Pate, weshalb Manualia kaum ,(für den juristischen Praktiker) Handliches, Nützliches', nämlich Rechtssätze (handy, useful [laws]) bedeutet. Wenn Stein dafür die Auswertung des Werkes in der Papiniansmasse geltend macht, ${ }^{113}$ so übergeht er, dass auch die zweifellos akademischen Parallelschriften von Pomponius in der Papiniansmasse exzerpiert wurden. [58] Es bleibt also bei der schlichten Bedeutung ,Handbücher’ i. S. v. ,Kurzgefasstes', auch wenn großenteils sehr spezielle Fragen behandelt sind.

Für diesen wohl werbend gemeinten Titel war Paulus womöglich gar nicht verantwortlich, sondern Schüler von ihm. Wie ich seinerzeit festgestellt habe, ${ }^{114}$ stammt die Schrift nur aus der Werkstatt des Paulus. Ein Drittel der 37 erhaltenen Fragmente ist durch die Fragmenta (iuris) Vaticana überliefert, der Rest durch die Digesten. Die einzige Doppelüberlieferung $^{115}$ ergibt, dass die Justinianer den Text sprachlich aufbesserten, wie sie es auch bei den pseudopaulinischen Sentenzen taten. ${ }^{116}$ Hier wie dort war das offenbar nötig, d. h. die Kompi-

${ }^{110}$ Peter Stein: Pauli libri tres manualium, in: RIDA 7 (1960), S. 484 u. 487. Unrichtig ist seine Angabe S. 485 u. Anm. 25, Plinius und Gellius würden den griechischen Buchtitel im Singular nennen.

${ }^{111}$ Ebd., S. 485.

112 Siehe etwa Franz Passow: Handwörterbuch der griechischen Sprache I 2, Leipzig 1847, S.

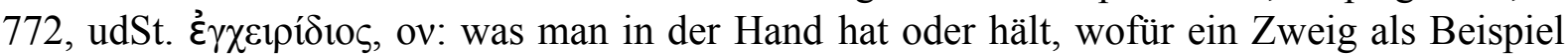
angeführt wird und sodann drei Konkretisierungen: a) Handhabe, Heft, Griff; b) bes. Handmesser, Dolch; und c) Handbuch, welche Bedeutung freilich erst später begegnet, zuerst bei Philostratos. Im gleichen Sinn, wenn auch kürzer, Hermann Menge: Enzyklopädisches Wörterbuch der griechischen und deutschen Sprache I, 2. Aufl., Berlin 1913, S. 201 udSt.

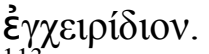

${ }_{113}$ Stein (wie Anm. 110), S. 486.

${ }^{114}$ Liebs: Hermogenians (wie Anm. 3), S. 48-50.

${ }^{115}$ Fragm. Vat. 55 = D. 45, 3, 26. Dazu Wieacker: Textstufen (wie Anm. 20), S. 382, der allerdings die verdeutlichende Einfügung von usum fructum für weniger elegant und daher vorjustinianisch erklärt. Von seiner Textkritik im Übrigen (S. 382-384) ist hier abzusehen; er konstatiert tiefgreifende Störungen, und zwar Parafrasen mit schwachem gedanklichen Eigengehalt und trocken-schulmäßigem, bis zur Art des Gajus von Autun sinkendem Niveau, was er Bearbeitern zuschreibt, ohne sich zu fragen, ob diese Mängel auch anders erklärt werden können.

${ }^{116}$ Siehe die von Detlef Liebs: Die pseudopaulinischen Sentenzen. Versuch einer neuen Palingenesie, II: Ausführung, ZRG RA 113 (1996), S. 132-242, hier 136-234, verzeichneten Abweichungen der Digesten- von der übrigen Überlieferung. 
latoren nahmen bei diesen Texten weniger an der sachlichen Aussage Anstoß, sondern an sprachlichen Unzulänglichkeiten; der dargestellte Rechtszustand sollte meist unverändert fortgelten. Schon bei Herstellung des Codex Iustinianus hatten sie sich der sprachlichen Fassung der rhetorisch aufgeblähten Gesetze der ersten christlichen Kaiser angenommen. ${ }^{117}$

Zur Beurteilung der Manualia empfiehlt sich also, von den unverbesserten Fragmenten in den Fragmenta Vaticana auszugehen und hier glättende Emendationen der Herausgeber erst einmal rückgängig zu machen. Dann stellt man fest, dass Wortschatz und Stil signifikant schlichter als in den unstreitig paulinischen Schriften sind und dass der Gedankengang oft unklar oder brüchig ist. Ein Beispiel: ${ }^{118}$

Idem (Paulus) lib. I Manualium

Actio de $u$ su fruct $u$ isdem modis perit, quibus ipse usus fructus, praeterquam non utendo; pecuniae quoque usus fructus legatus per annum non utendo, quia nec usus fructus est et pecuniae dominium fructuarii, non heredis est.

Die Klage auf Einräumung eines Nießbrauchs geht aus den gleichen Gründen unter wie der Nießbrauch selbst, außer durch Nichtgebrauch; auch (gemeint: ebenso wenig) ein vermachter Nießbrauch an Geld durch einjährigen Nichtgebrauch, weil das auch kein Nießbrauch ist und das Eigentum am Geld beim Nießbraucher, nicht beim Erben ist.

[59] Praeterquam non utendo besagt, dass Nichtausübung des Nießbrauchs nur den (schon eingeräumten) Nießbrauch selbst (erst einmal) erlöschen lässt, nicht auch die persönliche, auf

Einräumung des Nießbrauchs gerichtete actio de usu fructu, wenn das auch bestritten war. ${ }^{119}$ Mit pecuniae quoque usf. wird daran der Fall des Nießbrauchs an Geld geknüpft, der durch Nichtgebrauch nicht einmal selber erlischt, allerdings aus einem anderen Grund, weil nämlich bei diesem Gegenstand Nießbrauch im eigentlichen Sinn unmöglich ist, nur ein Quasinießbrauch; denn dieses Geld wird Eigentum des Nießbrauchers. Der Text spart das Prädikat non perit ein, aber nicht etwa, weil es kurz vorher schon einmal ausgesprochen worden wäre; dort war nur von perit die Rede; das non musste man dem praeterquam sinngemäß entnehmen. Die übliche Verschleierung dieses sprachlichen Defekts durch emendierende Einfügung von

\footnotetext{
${ }^{117}$ Siehe die von Theodor Mommsen (Hg.): Theodosiani libri XVI, I 2, Berlin 1905, festgehaltenen Änderungen der aus dem CTh in den CJ übernommenen Konstitutionen.

${ }^{118}$ Frg. Vat. 46.

${ }^{119}$ Siehe Just. 530 CJ 3, 33, 16; Iul. 7 dig. D. 7, 6, 3; u. dazu Giuseppe Grosso: Usufrutto e figure affini in diritto romano, 2. Aufl., Turin 1958, S. 389 u. Anm. 1 u. S. 502 Anm. 1; übersehen von Karl-Heinz Schindler: Justinians Haltung zur Klassik, Köln 1966, S. 71 f.
} 
non perit $^{120}$ oder non amittitur ${ }^{121}$ ist, so sehr sie in der Sache das Richtige trifft, abzulehnen. $^{122}$

Außerdem werden Beispiele unangenehm wortreich ausgeführt. ${ }^{123}$ Einfache gedankliche Ansätze werden einfallslos, aber schier endlos variiert. ${ }^{124}$ Andererseits finden sich wortwörtliche Anklänge an eine Stelle aus dem Sabinuskommentar des Paulus, ${ }^{125}$ sonst, soweit ersichtlich, zu keinem anderen erhaltenen juristischen Text. Die Erörterung beschränkt sich nicht auf elementare Fragen wie in den Institutionen des Gajus und Pseudo-Ulpians Regularum liber singularis; vielmehr will der Text durchaus in die Probleme tiefer eindringen und scheint immer wieder ein zielstrebiger Gedan[60]kengang durch. Deshalb liegt am nächsten, Mitschrift eines paulinischen Lehrvortrags anzunehmen, wobei viele Gedanken offenbar verkürzt festgehalten wurden; und wenn bestimmte Variationsmöglichkeiten in einer Reihe ähnlicher Fälle eintönig wiederkehren, ${ }^{126}$ so könnte das dadurch zustandegekommen sein, dass die Schüler den Lehrer bei jedem neuen Fall immer wieder danach fragten oder auch dieser es didaktisch geschickt fand, mehrmals auf diese Komplikationsmöglichkeit zurückzukommen.

Auf den werbenden Titel wird man durch die Kürze der Schrift verfallen sein. Dass sie in ihrer vollständigen Gestalt einen Überblick über alle Rechtsgebiete geboten hätte, die nach dem Digestensystem geordnet gewesen wären, hat Lenel zwar angenommen, jedoch vorschnell. ${ }^{127}$ Dafür sind die Erörterungen zum Nießbrauch zu breit angelegt und detailliert, ${ }^{128}$

${ }^{120}$ Bethmann-Hollweg, Huschke u. Theodor Mommsen, s. dessen Ausgabe, in: Col-lectio librorum iuris anteiustiniani III, Berlin 1890, S. 32 u. Anm. 6; ebenso Bernhard Kübler: Iurisprudentiae anteiustinianae reliquiae II 2, Leipzig 1927, S. 221 u. Anm. 1.

${ }^{121}$ Lenel: Palingenesia I (wie Anm. 19), Sp. 1135.

${ }^{122}$ Weitere Beispiele: In Frg. Vat. 49 wird die mit videamus, ne non possit durch das non nicht mehr offen, sondern schon mit negativer Tendenz gestellte Frage zu beantworten denn auch nicht mehr für nötig befunden, sondern nur noch eine Begründung der implizierten negativen Antwort angehängt. - Ähnlich Vat. 55 g. E. - Der Schlusssatz von D. 17, 2, 83 $\overline{\text {; will }}$ wohl nur besonders betonen, dass die ideellen Bruchteile an der gemeinsamen beweglichen Sache rechnerisch den realen Bruchteilen entsprechen, die vor Trennung der Sache vom Grundstück bestanden; Stein (wie Anm. 110), S. 481 f., nimmt nach anderen zu Unrecht eine Interpolation an. - In D. 50, 16, $227 \S 1$ überrascht immo, als nehme der Verfasser seine Aussage zurück, doch präzisiert er nur.

${ }^{123}$ Vat. 50, D. 8, 3, 38; 8, 4, 18; u. 17, 2, 83.

${ }^{124}$ Vor allem Vat. 48-50, 52 u. 57 zum befristeten und 50, 55 u. 58 zum bedingten Nießbrauch.

${ }^{125}$ Vgl. PM 1 D. 17, 2, 83 mit Paul. 6 Sab. D. 10, 3, 19 pr. u. dazu Stein (wie Anm. 110), S. 481-483.

${ }^{126}$ Oben Anm. 124

${ }^{127}$ Lenel: Palingenesia I (wie Anm. 19), Sp. 1135-1139, bes. Sp. 1135 Anm. 1. Ablehnend schon Stein (wie Anm. 110), S. 480 f. Auch bei den pseudopaulinischen Sentenzen, Hermogenians Iuris epitomae und den pseudoulpianischen Opinionen legte Lenel vorschnell das Digestensystem zugrunde, Liebs: Hermogenians (wie Anm. 3), S. 26-28 u. S. 115-130; ders.: 
für alle Rechtsgebiete hätten drei libri, auch wenn die anderen Gebiete weniger breit behandelt worden wären, bei weitem nicht ausgereicht. Dagegen passt dieser Umfang gut zu einem Produkt eines Unterrichtskurses. Vom Inhalt her müsste er fortgeschrittenen Studenten geboten worden sein. Welche Rechtsgebiete er genau erfasste, kann nicht mehr festgestellt werden. In den erhaltenen Fragmenten geht es hauptsächlich um Sachenrecht, ${ }^{129}$ daneben um Erbrecht, ${ }^{130}$ etwas Obligationen-, ${ }^{131}$ Prozess- ${ }^{132}$ und Vollstreckungsrecht. ${ }^{133}$ Das Werk lief bald wie ein vom Autor ediertes um und muss beliebt gewesen sein, wie man aus seiner ausgiebigen Verwertung durch den Kompilator der Fragmenta Vaticana um 320 in Rom ${ }^{134}$ schließen kann.

[61] III. Kleine Gelegenheitsarbeiten

\section{Mäcian, Distributio, item vocabula ac notae partium etc.}

Mäcians Schrift über Teile, Maße und Gewichte: Distributio, item vocabula ac notae partium in rebus, pecunia aere numerata, pondere, mensura, ist in zwei Handschriften des 10 . Jh. zusammen mit jüngeren Werken ähnlichen Inhalts, aber von Nichtjuristen unvollständig erhalten ${ }^{135}$ und umfasste offenbar weniger als ein Fünftel eines durchschnittlichen liber. Der überlieferte Text bricht mitten im Satz ab, war ursprünglich aber kaum viel länger. ${ }^{136}$

Mäcian hatte seine Gelegenheitsarbeit über Teile, Maße und Gewichte samt ihren Zeichen für seinen hochgeborenen Schüler, den Kronprinzen Mark Aurel, also um 146 n. Chr. ver-

Ulpiani Opinionum libri VI, in: TRG 41 (1973), S. 279-310, hier 300-305; u. ders.: Africa (wie Anm. 73), S. 111-113.

${ }^{128}$ Zwiespältig insoweit Stein (wie Anm. 110), s. bes. S. 487 f.; von einer collection of ... typical arguments kann keine Rede sein.

${ }^{129}$ Lenel: Pal. I, Sp. 1135 ff., Nr. 983-1001 aus Buch 1 u. Nr. 1010 f. aus Buch 2.

${ }^{130}$ Lenel: Pal. I, Sp. 1137 f., Nr. 1002 f. aus Buch 1 u. Nr. 1007-9 nebst Nr. 1017 aus Buch 2.

${ }^{131}$ Lenel: Pal. I, Sp. 1138, Nr. 1005 f. u. Nr. 1014-16 aus Buch 2.

${ }^{132}$ Lenel: Pal. I, Sp. 1135, Nr. 981 f. aus Buch 1.

${ }^{133}$ Lenel: Pal. I, Sp. 1139, Nr. 1012 f. aus Buch 2.

${ }^{134} \mathrm{Zu}$ deren Datierung und Lokalisierung Liebs: Italien (wie Anm. 15), S. 150-162.

135 Paris, Bibliothèque Nationale, Cod. Lat. 8680; u. Rom, Biblioteca apostolica Vaticana, Cod. Lat. 3852. Ausgabe: Theodor Mommsen, in: Abh. d. kgl. Sächs. Ges. d. Wiss. 3, Leipzig 1857, S. 280-295; u. Emil Seckel/Bernhard Kübler, in: Iurisprudentiae anteiustinianae reliquiae I, 6. Aufl., Leipzig 1908, S. 408-418. Dazu Liebs: Jurisprudenz (wie Anm. 10), S. $132=$ $\S 419.2$ W. 2.

${ }^{136}$ Vgl. Mommsen (soeben Anm. 135), S. 287. 
fasst. Die zunächst nur für ihn ausgearbeitete Schrift war für sich keine packende Lektüre, und da sie eine ganze Buchrolle bei weitem nicht füllte, kam eine Edition nur zusammen mit anderen Werken, die dazu passten, in Betracht; ${ }^{137}$ und so finden wir sie auch überliefert. Aber veröffentlicht wurde sie wohl erst später; ursprünglich scheint sie lediglich zum internen Gebrauch verfasst worden zu sein, wenn auch nicht in einer Schule, sondern für privatissime erteilten Rechtsunterricht.

\section{Anonymus, De gradibus cognationum}

In den Handschriften des Handbuchs der Verwaltungs- und Militärstruktur des römischen Reichs der Spätantike, der sogenannten Notitia dignitatum, findet sich neben kleineren ähnlichen Verzeichnissen wie der Notitia urbis Constantinopolitanae auch ein kurzer, knapp anderthalbseitiger Text, der die ersten sechs Verwandtschaftsgrade ohne weitere Bemerkungen erklärt. ${ }^{138}$ Im Vergleich mit entsprechenden Ausführungen aus Werken bekannter Juristen ${ }^{139}$ erweist er sich als besonders karg, weshalb zu erwägen [62] ist, ob wir es auch hier mit einem nicht zur Veröffentlichung, sondern, wie womöglich auch die Notitia dignitatum selbst, nur zum internen Gebrauch der Behörden bestimmten Text zu tun haben.

\section{4. Die sogenannten Stemmata agnationis und cognationum?}

Inhaltlich und vom Umfang her verwandt sind die Schaubilder der Verwandtschaftsbeziehungen in männlicher (agnati) und in gemischter mitsamt rein weiblicher Linie (cognati), die in Handschriften der Lex Romana Visigothorum anzutreffen sind: einmal ein sogenanntes Stemma agnationis, das entweder als Ergänzung eines vorgeschalteten Auszugs aus dem einschlägigen Abschnitt in Isidors Etymologien ${ }^{140}$ erscheint oder im Text des Breviars nach den theodosianischen Novellen; ${ }^{141}$ Volterra datierte es, weil es nur das alte Agnationsprinzip erklärt,

${ }^{137}$ Mazal (wie Anm. 1), S. 106.

138 Ausgaben: Paul Krüger, in: Collectio librorum iuris anteiustiniani II, Berlin 1878, S. 166 f.; u. Seckel/Kübler: Iurisprudentiae (wie Anm. 135) II 1, 1911, S. 183 f.

${ }^{139}$ D. $38,10,1$ u. 3 aus Gajus, Ad edictum provinciale VIII; D. 38, 10, 10 aus Paulus, De gradibus et adfinibus et nominibus eorum liber singularis; u. D. 38, 10, 4 aus Modestin, Pandectae XII.

${ }^{140}$ Isidor, Etymologiae 9, 5 f. So Paris, BN Lat. 4410 s. IX, B1. 2-4, s. Gustav Hänel (Hg.): Lex Romana Visigothorum, Leipzig 1949, S. LXIV; u. Leiden, UB 114 s. IX in., B1. 1-8, s. Hänel, ebd., S. LXXVII; u. Hubert Mordek: Bibliotheca capitularium regum Francorum manuscripta, München 1995, S. 502.

${ }^{141}$ So Paris, BN Lat. 4412 s. IX, B1. 72-77: im Anschluss an die Novellen, s. Hänel (soeben Anm. 140), S. LXI u. Anm. 176; u. Rom, Bibl. Vat. reg. Lat. 1023 s. IX 2/2, B1. 64-68: bei 
vor Gajus. ${ }^{142}$ Jünger sind die verschieden ausgestalteten Stemmata cognationum. ${ }^{143}$ Bei all diesen kleinen Arbeiten liegt der Gedanke nahe, dass sie wie die Interpretationen des Breviars einst lediglich im Unterricht verwandt wurden, mündlichen Unterricht begleiteten. Nicht auszuschließen ist jedoch, dass sie aus größeren, regelrecht edierten Werken stammen.

\section{Spätantike Unterrichtsskripten}

Seit Konstantin, der durch Gesetz einzelne Werke der klassischen Juristen wie die Noten Ulpians und des Paulus zu Papinians Responsen und Quästionen verbot ${ }^{144}$ und andererseits Pseudepigrafa wie die pseudopaulini[63]schen Sentenzen für paulinisch zu halten und zu ehren befahl, ${ }^{145}$ nahm sich kein Jurist mehr heraus, ein neues juristisches Werk im eigenen Namen regelrecht zu veröffentlichen, obwohl Juristen weiterhin lehrten und berieten. Ihr Niveau ist schwer zu beurteilen, doch sollten wir uns hüten, es von vornherein gering einzuschätzen. Wir haben aus dieser Zeit nur mehr Fragmente von Pseudepigrafa wie den pseudoulpianischen Opinionen in sechs Büchern, um 325 n. Chr. anzusetzen; ${ }^{146}$ Anonymes wie das griechische Schriftchen De actionibus, ${ }^{147}$ das um 500 n. Chr. entstand; ${ }^{148}$ und, wenn wir von den kleinen und großen offiziellen Texten, den einzelnen Gesetzen und den Kodifikationen, absehen, eben Esoterisches.

\section{Der Gajus von Autun}

Die Stadtbibliothek von Autun verwaltet eine der Kirche von Autun gehörige Handschrift der Institutionen von Cassian, die sich als Palimpsest erwies. 15 Blätter dieser Handschrift waren ursprünglich mit einer spätantiken Parafrase der Institutionen des Gajus beschrieben. ${ }^{149}$ Erhal-

zusätzlichen Novellen, s. Hänel, ebd. S. LXI u. Anm. 181; u. Mordek (soeben Anm. 140), S. 842. Ausgaben: Hänel, ebd., Tafeln bei S. 456 f., Forma I; Krüger: Collectio II (wie Anm. 138), S. 168; u. Seckel/Kübler: Iurisprudentiae II 1 (wie Anm. 138), S. 185-187.

${ }^{142}$ Edoardo Volterra: La graduum agnationis vetustissima descriptio segnalata da Cujas, in: Atti della Accademia Nazionale dei Lincei, anno CCCLXXV - 1978, Memorie: Classe di Scienze morali, storiche e filologiche, ser. 8, vol. 22 (1978), S. 1-109 mit 17 Abb.

143 Ausgabe: Hänel (wie Anm. 140), Tafeln bei S. 456 f., Forma II-V.

${ }^{144}$ CTh 1, 4, 1 vom 28. Sept. 321; vgl. schon 9, 43, 1 vom 14. Sept.

${ }^{145}$ CTh 1, 4, 2 vom 27. Sept. 328.

${ }^{146}$ Liebs: Ulpiani (wie Anm. 127), S. 279-310, hier 280-294.

${ }^{147}$ Neu herausgegeben und kommentiert von Francesco Sitzia: De actionibus. Edizione e commento, Mailand 1973.

${ }^{148}$ Sitzia, ebd., S. 75-111.

${ }^{149}$ Autun, Bibliothèque municipale, Ms. Lat. 28 (früher 24, nicht 21). Dazu jetzt ausführlich José-Domingo Rodríguez Martín: Fragmenta Augustodunensia, Granada 1998; zur Qualität 
ten sind auf diesen 15 Blättern Bruchstücke des Kommentars zu Stellen aus dem ersten, zweiten und vierten Buch der Institutionen, ${ }^{150}$ die Stellen aus dem vierten Buch zum Teil weniger breit. Einst wird der Kommentar vollständig gewesen sein. Wenn die durchschnittliche Ausführlichkeit der erhaltenen Kommentarstücke repräsentativ für den vollständigen Kommentar ist, haben wir von diesem knapp sechs vom Hundert; ${ }^{151}$ er hätte also etwas mehr als 250 [64] solcher Blätter, 500 S., gefüllt und diese hätten etwas weniger als doppelt so viel Raum wie der Grundtext eingenommen, ungefähr sieben libri. ${ }^{152}$

Der Text war ursprünglich nicht zur Veröffentlichung bestimmt, sondern stellt die redigierte Fassung eines mitgeschriebenen Lehrvortrags dar, ${ }^{153}$ eines Kurses an Hand der Institutionen des Gajus von Buch 1 bis 4. Er wandte sich an blutige Anfänger, denen praktisch verwertbare Rechtskenntnisse beigebracht werden sollten. ${ }^{154}$ Das geschah didaktisch geschickt. ${ }^{155}$ Der Kurs fand im 4. oder frühen 5. Jh. statt, etwa zwischen 300 und 420 n. Chr., ${ }^{156}$ und zwar in einer westlichen Provinz, wobei Autun selbst nahe liegt. ${ }^{157}$ Die erhaltenen Fragmente stammen nicht aus der Erstausgabe, sondern aus einer Abschrift oder der Abschrift einer solchen usw., ${ }^{158}$ hergestellt im 4. oder 5. Jh. in Südgallien, wozu hier auch Autun zählt; möglicherweise entstand die Handschrift auch in Norditalien. Benutzt wurde feinstes Pergament. ${ }^{159}$ Es handelte sich also um eine anspruchsvolle Ausgabe eines ursprünglich esoterischen Texts.

des Pergaments S. 23-25, zu den Eigentumsverhältnissen S. 6 u. 13 f., S. 14-16 auch zur Signatur. Diese und andere Handschriften dort gehören dem Domkapitel und dem Grand Séminaire d'Autun. Die vier gestohlenen Blätter aus dieser Handschrift, jetzt Paris, BN, nouv. acq. 1629, B1. 17-20, haben einen anderen Ersttext.

${ }^{150}$ Erhalten ist Kommentar zu Gai 1, 93-97 u. 124-29; 2, 158; 162-71 u. 250-71; 4, 39; 45; 80-85; 91-94 u. 103-9, wenn auch zum Teil nur mehr sehr lückenhaft lesbar.

${ }^{151}$ Die in der vorigen Fn. aufgelisteten Gajusstellen füllen in der Ausgabe von Manthe (wie Anm. 36) rund $11 \frac{1}{2}$ Seiten, das sind 5,75\% des ganzen Gajustexts von rund 200 Seiten: 191 leserlichen und geschätzten neun unleserlichen oder verlorenen.

${ }^{152}$ In der Ausgabe von Kübler (wie Anm. 120), S. 434-460, nimmt der Kommentar 27 S. ein, weshalb der ganze Kommentar bei Zugrundelegung des in der vorigen Fn. errechneten Verhältnisses hier $470 \mathrm{~S}$. gefüllt hätte. Der Gajustext nahm in dieser Ausgabe: Iurisprudentiae I (wie Anm. 135), S. 141-396, 256 leserliche Seiten ein, mit dem Unleserlichen und Verlorenen geschätzte 270, je liber also durchschnittlich $67 \frac{1}{2} 2$ Seiten.

${ }^{153}$ Das ist unumstritten, s. zuletzt Rodríguez Martín (wie Anm. 149), S. 427-439, bes. S. 436438 u. $481 \mathrm{f}$.

${ }^{154}$ Rodríguez Martín, ebd., S. 447-461.

${ }^{155}$ Martín, ebd., S. 463-474.

${ }^{156}$ Martín, ebd., S. 505-509.

${ }^{157}$ Martín, ebd., S. 493-503; s. a. S. 24.

${ }^{158}$ Martín, ebd., S. 481.

${ }^{159}$ Martín, ebd., S. 23-28. 


\section{Die sogenannte Gajusepitome}

Ein anderer Lehrgang an Hand der Institutionen des Gajus, allerdings wohl von Anfang an nur noch der ersten drei Bücher und auch im Übrigen kürzer, ist uns im westgotischen Römergesetz von 505/6 erhalten. ${ }^{160}$ Dessen erster Teil enthält die fortgeltenden Leges: Kaisergesetze seit Konstantin; und der zweite, kürzere Teil das fortgeltende Ius: Auszüge aus Juristenschriften, beginnend mit einem kurzen Text, der Liber Gaii überschrieben ist und heute Gajusepitome genannt wird. ${ }^{161}$ Sie wurde nicht erst für die Lex Romana hergestellt, sondern ist, wie fast alles in diesem Gesetz, älter; allen Anzeichen nach stammt sie aus dem frühen 5. Jh. und entstand sie in Gallien. Es han[65]delt sich um Aufzeichnungen eines Rechtslehrers für mündlichen Unterricht, die hie und da im Unterricht selbst weiter auszuführen waren. ${ }^{162}$ Die westgotischen Kompilatoren haben auch diesen Text nur gekürzt aufgenommen, ${ }^{163}$ weshalb zu fragen ist, wie sehr sie kürzten. Stillschweigend geht man im Allgemeinen davon aus, dass der Text auch ursprünglich nicht viel umfangreicher war, sondern schon immer nur einen kleinen Teil des Stoffs der Institutionen behandelte. Jedenfalls war der gajanische Grundtext etwa sechsmal so ausführlich wie der vorliegende Epitometext. ${ }^{164}$ Und wenn man auch in Rechnung stellen muss, nicht nur, dass die Kompilatoren der Westgoten manches weggelassen haben, sondern auch, dass der Lehrer sich ergänzende Ausführungen im Unterricht vorbehalten, nur ein Gerüst aufgezeichnet hatte, so kam er doch ohne Einteilung in Bücher aus; ${ }^{165}$ dieser Lehrgang war offenbar wesentlich kürzer als der von Autun, führte aber gleichermaßen in das geltende Recht ein, d. h. war bemüht, zu praktisch verwertbaren Rechtskenntnissen hinzuführen, wenn auch nicht schon, Praktikern zu helfen. ${ }^{166}$ Ediert wurde er vor seiner Über-

${ }^{160} \mathrm{Zu}$ ihm genauer Liebs: Gallien (wie Anm. 7), S. 166-169.

${ }_{161}$ Ausgabe: Kübler (wie Anm. 120), S. 395-431. Dazu zuletzt Liebs: Gallien (wie Anm. 7), S. 127-33.

${ }^{162}$ GE 2, 9, 4 heißt es beim eidlichen Versprechen des Freigelassenen an den Freilasser, ihm Dienste zu leisten: exponendum hic quid sit donum vel munus vel operae; und in der Gothaer Handschrift der Lex Romana Visigothorum vor dem Text von GE 2, 6: Hic Pauli sententiis lege. Dazu Liebs: Gallien (wie Anm. 7), S. 127 f.

163 Jedenfalls wurde auch der Liber Gaii in einzelnen Breviarhandschriften aus einem vollständige(re)n Exemplar desselben aufgefüllt, wenn auch nur um einen Titel (von 18): GE 2, 4, s. Liebs: Gallien (wie Anm. 7), S. 133 u. Anm. 54. Zu solchen Supplierungen der ins Breviar eingegangenen Auszüge s. a. Liebs, ebd., S. 98, 99 u. 110.

${ }^{164}$ Bei Kübler (wie Anm. 120), S. 398-431, füllt er knapp 33 S., während ein Gajusbuch dort durchschnittlich gut $67 \mathrm{~S}$. füllte, s. oben Anm. 152.

${ }^{165}$ Friederike Bauer-Gerland, in: ZRG RA 114 (1997), S. 495-501, hier S. 499-501.

${ }^{166}$ So aber Gian Gualberto Archi: L'Epitome Gai, Mailand 1937, doch s. Bauer-Gerland (soeben Anm. 165), S. 495-501; u. Liebs: Gallien (wie Anm. 7), S. 127. 
nahme durch die Westgoten anscheinend nicht, sondern lief wohl, etwas oder auch merklich ausführlicher, im Übrigen aber in der Form um, in der wir ihn bei den Westgoten antreffen. ${ }^{167}$

\section{4. Die sogenannten Summaria antiqua zum Codex Theodosianus und andere Summen}

In den Summaria antiqua zum Codex Theodosianus, kurze Randsummen in unserer einzigen vollständigen Handschrift, freilich nur der zweiten Hälfte desselben, haben wir Aufzeichnungen eines Rechtslehrers vor uns, der einen Kurs zum Codex Theodosianus gab und jedes oder fast jedes Gesetz [66] kurz vorstellte. ${ }^{168}$ Die Summaria haben eine offenbar absichtlich unfertige Form, die nicht auf einer Schülermitschrift beruhen kann; fremde Augen sollten sie wohl gar nicht sehen. ${ }^{169}$ Der Kurs kann um 450 n. Chr. datiert und in einer urbs Siziliens, am ehesten Syrakus, lokalisiert werden ${ }^{170}$. Vermutlich waren diese Summarien schon ursprünglich lediglich am Rande der Theodosianus-Ausgabe des Lehrers notiert und wurden sie zusammen mit dem Gesetzeswerk überliefert, woher wir sie kennen.

Auf den 1904 verbrannten Turiner Fragmenten einer Handschrift des Theodosianus aus dem 6. Jh. waren vereinzelte Randbemerkungen zum Theodosianus von anderer Hand erhalten, aber ebenso alt: ${ }^{171}$ gelegentliche kurze Summen und vor allem Querverweise, auch auf Stellen im Codex Gregorianus. Hier scheint es sich um Zutaten eines Benutzers zu handeln, wie sie öfter begegnen, z. B. auch in der Breviarhandschrift von León. ${ }^{172}$

\footnotetext{
${ }^{167}$ Bei einer Edition wären die oben Anm. 160 angeführten Vermerke doch wohl gestrichen worden.

${ }^{168}$ Cod. Vat. reg. Lat. 866. Neue Ausgabe von A. J. Boudewijn Sirks: Summa Antiqua Codicis Theodosiani, Amsterdam 1996, rez. Detlef Liebs, in: ZRG RA 118 (2001), S. 496-501.

${ }^{169}$ Liebs: Italien (wie Anm. 15), S. 182 f.; Gräzismen S. 180.

${ }^{170}$ Liebs: Italien (wie Anm. 15), S. 178-182; s. a. Mariagrazia Bianchini, in: Labeo 36 (1990), S. 105. Zur abweichenden Lokalisierung und Datierung durch Sirks s. Liebs, in: ZRG RA 118 (2001), S. 499 f.; doch s. jetzt wiederum Sirks: The Theodosian Code. A Study (Friedrichsdorf 2007), S. 224-235.

${ }^{171}$ Paul Krüger: Codicis Theodosiani fragmenta Taurinensia, Berlin 1880, S. 16, 24, 26, 30, 72, 75 u. 78 f.; dazu S. 14; Theodor Mommsen (wie Anm. 117), I 1: Prolegomena, S. XLII; u. Sirks (wie Anm. 168), S. 115-119.

${ }^{172}$ León, Biblioteca Catedral 15 (= CLA XI, Nr. 1637; Faksimile-Ausgabe s. oben Anm. 9), so zu IT 4, 4, 1 u. 4, 9, 1, zusammen etwa 50.
} 


\section{6. Interpretationen zu den Paulussentenzen}

Gleichfalls durch das westgotische Römergesetz ist uns ein Interpretationenapparat zu einem Auszug aus den Paulussentenzen überliefert. ${ }^{173}$ Auch er wurde nicht erst von den westgotischen Kompilatoren geschaffen, sondern entstand schon im mittleren 5. Jh. in Südgallien. ${ }^{174}$ Den 236 wahrscheinlich von ein und demselben Autor stammenden Interpretationen ${ }^{175} \mathrm{zu}$ [67] rund 250 Sentenzen ${ }^{176}$ lag ein schmaler Sentenzenauszug zugrunde, der nur etwa ein Viertel bis Fünftel der vollständigen Paulussentenzen enthielt. ${ }^{177}$ Die einzelnen Interpretationen sind fast durchweg wie der Grundtext objektiv stilisiert. Auch sie gehen auf Rechtsunterricht zurück, diesmal an Hand des Sentenzenauszugs, der sich nur für Fortgeschrittene eignete. Das Niveau ist freilich bescheiden. ${ }^{178}$ Die Aussagen des Grundtexts wurden auf leicht verständliche Weise entfaltet, insbesondere, wenn er gedrängt formuliert war; wo es nötig schien, wurde er aktualisiert, aber ohne die Aussage des Grundtexts ausdrücklich zu verwerfen. ${ }^{179}$ Der Lehrer ist daran erkennbar, dass immer wieder sprachliche Fragen im Vordergrund stehen ${ }^{180}$ und öfter kleine Traktate ${ }^{181}$ und Definitionen ${ }^{182}$ eingeschoben sind; auch die gelegentlichen Querverweise ${ }^{183}$ lassen sich so deuten und zumal die, wenn auch seltene, erste und zweite Person Plural. ${ }^{184}$ Das Werklein war offenbar zusammen mit dem erläuterten Sentenzenauszug verbreitet. ${ }^{185}$

${ }^{173} \mathrm{Hg}$. von Hänel (wie Anm. 140), S. 338-445, zusammen mit dem Sentenzenauszug des Breviars; gesondert von Max Kaser/Fritz Schwarz: Die Interpretatio zu den Paulussentenzen, Köln 1956; und mit den Sentenzen von Maria Bianchi Fossati Vanzetti: Pauli sententiae. Testo e interpretatio, Mailand 1995. Dazu vor allem Hartwig Schellenberg: Die Interpretationen zu den Paulussentenzen, Göttingen 1965; s. a. Liebs: Gallien (wie Anm. 7), S. 146 f.

${ }^{174}$ Schellenberg, ebd. S. 65 f. Datierung: S. 62-68.

${ }^{175}$ Schellenberg, ebd. S. 36-38.

${ }^{176}$ Interpretationen zu zwei oder mehr Sentenzen hat Schellenberg, ebd., S. 55-60, in größerer Zahl als zuvor ausgemacht.

${ }_{177}^{17}$ Schellenberg, ebd., S. 39-61.

${ }^{178}$ William Warwick Buckland, in: Law quarterly review 60 (1944), S. 361-364, stellte sachliche Fehler zusammen, freilich mit klassizistisch eiferndem Zungenschlag, ohne Sinn für nachklassische Entwicklungen.

${ }^{179}$ Mit Nachweisen kurz zusammengefasst bei Liebs: Gallien (wie Anm. 7), S. 146.

${ }^{180}$ Siehe etwa IP 4, 1, 6; 4, 10, 2 u. 5 u. 7.

${ }^{181}$ Z. B. IP 1, 7, 1 f. u. 4; 1, 19, 1; 3, 6, 7 u. 9-12; 5, 2, 1; u. 5, 6, 1.

${ }^{182}$ Z. B. IP $1,2,1 ; 2,3,1 ; 2,14,3 ; 2,22,1 ;$ u. 5, 30, 1.

${ }^{183}$ Z. B. IP $1,19,1 ; 2,18,11 ; 3,9,72 ;$ u. 5, 36, 1.

184 2. Pers. Pl. IP 4, 13, 2; 1. Pers. P1. IP 5, 2, 1 u. 2.

${ }^{185}$ Schellenberg (wie Anm. 173), S. 38-43. 
In Nachträgen zum Breviar verstreut überlieferte weitere Interpretationen zu Paulussentenzen ${ }^{186}$ stammen offenbar von anderen Autoren, dienten aber wohl dem gleichen Zweck.

\section{8. Die Interpretationen zum Codex Gregorianus und zum Codex Hermogenianus}

Zum Codex Gregorianus, der vollständig etwa 4000 Konstitutionen enthielt, haben wir Reste eines Interpretationenapparats im westgotischen Römergesetz beim dortigen GregorianusAuszug. ${ }^{187}$ Dieser enthält 23 Konstitutionen und zehn Interpretationen dazu. Der Apparat wird ursprünglich [68] umfangreicher gewesen sein, doch wird schon dem vollständigen lediglich ein Auszug aus dem Gregorianus zugrundegelegen haben. Auch diese Interpretationen sind offenbar aus mündlichem Rechtsunterricht hervorgegangen, in diesem Fall aus einem Konstitutionenkurs; anscheinend haben auch hier Schüler (zum Teil nach Diktat?) sorgfältig mitgeschrieben. ${ }^{188}$ Kaiserkonstitutionen studierte man am Ende des Studiums als weiter Fortgeschrittener. ${ }^{189}$ Auch dieser Kurs fand in Südgallien, ${ }^{190}$ aber wohl erst um $470{ }^{191}$ statt.

Zum Codex Hermogenianus gab es ebenfalls derlei Interpretationen, doch ist nur eine einzige erhalten. ${ }^{192}$

9. - 11. Interpretationen zum Codex Theodosianus samt Novellen

Zahlreich überliefert, in diesem Fall nicht nur durch das Breviar und seine Erweiterungen, sind Interpretationen ${ }^{193}$ zur ersten offiziellen Gesetzessammlung, dem Codex Theodosianus mitsamt den dazugehörigen Novellen, wenn die Menge im Verhältnis zur interpretierten Textmenge auch nicht besonders groß ist. Erhalten sind 16 Interpretationen zum Theodosia-

\footnotetext{
${ }^{186}$ Nachweise bei Liebs: Gallien (o. Fn. 7), S. 147 u. Anm. 134; s. schon Schellenberg, ebd., S. 19 u. 50.

${ }^{187}$ Hg. Hänel (wie Anm. 140), S. 446-451; u. Paul Krüger, in: Collectio III (wie Anm. 120), S. 221-233, wo z. B. auf S. 233, App. zu Z. 15, Hänel korrigiert wird. Zum Werk Nicole Kreuter, Römisches Privatrecht im 5. Jh. n. Chr., Berlin 1993; u. Liebs: Gallien (wie Anm. 7), S. $147 \mathrm{f}$.

${ }^{188}$ Kreuter, ebd., S. 26-69; s. a. S. 94 u. 96-117.

${ }^{189}$ Vgl. zum vorjustinianischen Osten Schulz: Geschichte (wie Anm. 20), S. 351 u. Anm. 12 f.

${ }^{190}$ Kreuter, ebd., S. 70 f.

${ }^{191}$ Kreuter, ebd., S. 72-74, doch s. a. Liebs: Gallien (wie Anm. 7), S. 148 u. Anm. 142.

${ }^{192}$ IH 2, dazu Kreuter, ebd., S. 119 f. IH 1 stammt nach Kreuter, S. 118 f., von den westgotischen Kompilatoren.

${ }^{193}$ Vollständig ediert von Theodor Mommsen (wie Anm. 117), zu den Novellen von Paul M. Meyer, ebd. II. Die wenigen nicht im Breviar überlieferten Interpretationen (Mommsen I, S. 188-191 aus der Hs. Vat. reg. 520) erscheinen ohne Unterschied in gleicher Gestalt.
} 
nus außerhalb der alarizianischen Kodifikation, und durch sie weitere 408 zum Theodosianus und seinen Novellen. ${ }^{194}$ Nur ein sehr kleiner Teil davon stammt aus der Feder der Kompilatoren der Lex Romana Visigothorum, der Großteil aus älteren Interpretationenapparaten. ${ }^{195}$ Die von den Westgoten ausgebeuteten Apparate begleiteten vermutlich nur Auszüge aus dem Theo[69]dosianus nebst Novellen. Die vorhandenen Anhaltspunkte deuten auf Entstehung im mittleren oder späteren 5. Jh., ${ }^{196}$ am ehesten wieder in Gallien, wo unsere Überlieferung einsetzt.

Herkunft aus Rechtsunterricht wird immer wieder deutlich. Mehrmals treffen wir auf Stellen, wo der Autor anmerkt, dass etwas noch zu vertiefen sei. ${ }^{197}$ So heißt es zu CTh 3, 13, 2 zum Recht des Geschiedenen, einen Teil der Mitgift einzubehalten, am Schluss:

De retentionibus vero, quia hoc lex ista non evidenter ostendit, in iure, hoc est in Pauli Sententiis sub titulo De dotibus requirendum aut certe in Pauli Responsis sub titulo De re uxoria.

Über das Einbehaltungsrecht aber ist, weil dieses Gesetz das nicht deutlich aufzeigt, in der Rechtsliteratur, das heißt in den Paulussentenzen im Titel Über Mitgift nachzuschlagen oder jedenfalls in den paulinischen Bescheiden im Titel Über das Frauengut.

Und zu CTh 3, 16, 2 heißt es im gleichen Zusammenhang am Schluss:

Propter communes vero liberos, si fuerint, ea praecipit (haec lex) observari, quae in iure de retentionibus statuta sunt pro numero filiorum, quod Paulus in libro $<$ septimo $>$ Responsorum dicit sub titulo De re uxoria.

Wegen gemeinsamer Kinder aber, wenn es welche gegeben hat, ordnet es (dieses Gesetz) an, dass das beobachtet wird, was in der Rechtsliteratur über Einbehaltungen bestimmt ist je nach Zahl der Kinder, was Paulus im $<$ siebenten $>$ Buch der Bescheide im Titel Über das Frauengut sagt.

Der in der ersten Stelle angeführte Sentenzentitel erscheint zwar auch im Breviar, ${ }^{198}$ aber nur stark gekürzt, vor allem ohne Sentenz zur Retention. Und die Responsen von Paulus waren dem Breviar fremd, weshalb dieser Verweis, und jener ebenso, in dem Gesetzbuch, das

\footnotetext{
${ }^{194}$ Nachweise bei Liebs: Gallien (wie Anm. 7), S. 149 u. Anm. 146-8, doch hat CTh 4, 12, 1 aus Vat. reg. 520 B1. 94 keine Interpretatio. $\mathrm{Zu}$ den Paulussentenzen, aus denen das Breviar nur ein gutes Drittel so viel Text wie aus Theodosianus und Novellen aufgenommen hat, haben wir 236 Interpretationen.

${ }^{195} \mathrm{Zu}$ dem eigenen, nur mehr in kleinen Bruchstücken fassbaren Interpretationenapparat der Theodosianus-Fragmente auf Bl. 94 u. 95 der Hs. Vat. reg. 520 (zu ihnen Mommsen, wie Anm. 171, S. LXXXVI f.) s. Liebs: Gallien (wie Anm. 7), S. 148 f. u. Anm. 148 f. Auch die durch das Breviar und seine Komplettierungen überlieferten Interpretationen sind recht unterschiedlich, so dass ihnen mehrere Apparate zugrundeliegen werden, s. Liebs, ebd., S. 148-50. ${ }^{196}$ Liebs: Gallien (wie Anm. 7), S. 154 f.

${ }^{197}$ Liebs, ebd., S. $151 \mathrm{f}$.

${ }^{198}$ Heute Titel 2, 21B, im Breviar 2, 22, bei Liebs: Die pseudopaulinischen Sentenzen (wie Anm. 116), S. 163: 2, 24.
} 
ausschließliche Geltung beanspruchte, ${ }^{199}$ einem voralarizianischen Text entnommen sein muss, eben dem voralarizianischen Interpretationenapparat; er kann nur versehentlich stehen geblieben sein. Ebenso versehentlich stehen geblieben und folgerichtig in manchen Handschriften nachträglich getilgt sind zahlreiche Stellen in den Interpretationen, wo ganz allgemein vermerkt ist, dass weitere Ausführungen mit Hilfe der klassischen Rechtsliteratur zu machen sind: Hic de iure, aus der Rechtsliteratur, addendum, querendum, requirendum oder ähnlich, oft mit genauerer Angabe des Gegenstands: quid sit lex Papia, de revocandis donationibus und ähnlich. ${ }^{200}$ Daraus ist zu entnehmen, dass wir es bei den betreffenden Apparaten mit Aufzeichnungen eines Lehrers zu tun haben, die unvollständig ausformuliert waren; nicht mit einer Mit[70]schrift von Schülern. Der jeweilige Kurs hatte Aneignung des Stoffs der jüngsten Gesetzessammlung zum Gegenstand.

\section{Das sogenannte Syrisch-römische Rechtsbuch}

Auch das syrisch-römische Rechtsbuch ${ }^{201}$ war ursprünglich, in seiner griechischen Fassung, kein Rechtsbuch, sondern ein aus anspruchsvollem Rechtsunterricht hervorgegangener Begleittext. ${ }^{202}$ Der Unterricht fand um $475^{203}$ in einer Stadt des Orients statt, wohl Antiochien, und der Lehrer hieß Ambrosius. ${ }^{204}$ Die einzelnen Abschnitte oder Paragrafen sollten den Hörer an einen bestimmten normativen Grundtext heranführen, auch wenn dieser nur noch zum geringen Teil ausgemacht werden kann. Hauptsächlich waren es Konstitutionen aus den bekannten drei Codices und aus dem mittlerweile erreichten Bestand an neueren Konstitutionen. ${ }^{205}$ Der jeweilige Grund- oder Vorlagetext hatte dem Hörer vorgelegen, war ihm vielleicht zuvor diktiert worden, ohne jedoch mittradiert zu werden. Der Lehrer muss sehr frei und selbständig vorgegangen sein, weshalb wir die Grundtexte nur noch zu etwa einem Sechstel ermitteln können. Freilich sind uns auch die in Betracht kommenden Grundtexte selbst, insbesondere der privatrechtliche Teil des Codex Theodosianus, nur zum geringeren Teil erhalten;

${ }^{199}$ Lex Rom. Visig, Commonitorium, Satz 3-6.

${ }^{200}$ Nachweise bei Liebs: Gallien (wie Anm. 7), S. 152 Anm. 162.

${ }^{201}$ Jetzt mit Kommentar hg. Walter Selb/Hubert Kaufhold: Das Syrisch-römische Rechtsbuch, 3 Bde., Wien 2002, rez. Detlef Liebs/Peter Nagel, in: ZRG RA 121 (2001), S. 559-571/571573.

${ }^{202}$ Selb seit 1964, s. jetzt vor allem ders., ebd., III, S. 7-42; zum hohen juristischen Niveau Selb/Kaufhold, ebd., I, S. 39 f., 42 oben, 46, 50, u. III, S. 43-269.

${ }^{203} \mathrm{Selb} /$ Kaufhold, ebd., I, S. 43-46.

${ }^{204}$ Selb/Kaufhold, ebd., I, S. 46-50; u. dazu Liebs, in: ZRG RA 121, S. 560 unten.

205 Überblick über die bisher ermittelten Vorlagen bei Selb/Kaufhold, ebd., III, S. 315 unter 7;

s. a. Liebs, in: ZRG RA 121, S. 561-563. 
von den Codices Gregorianus und Hermogenianus fehlt uns überhaupt noch viel, wenn auch der Codex Iustinianus einen beträchtlichen Teil - z. T. interpoliert - bewahrt hat.

Diesem Kurs und damit dem in ihm sichtbaren östlichen Rechtsunterricht außerhalb der berühmten Zentren Beirut und Konstantinopel scheint also eine eigene Zusammenstellung von Stücken oder ganzen Partien aus den im späten 5. Jh. n. Chr. aktuellen römischen Normtexten zugrundegelegen zu haben: zu den ersten 81 Paragrafen Texte aus den Codices Gregorianus und Hermogenianus, zunächst hauptsächlich zum Erbrecht; sodann, zu §§ 82-104, solche aus dem Theodosianus; und schließlich, zu $\S \S 105-130$, neuere Gesetze. ${ }^{206}$ Dabei wurde aber schon in den früheren Teilen, wenn es tunlich zu sein schien, auf Novellen ebenso wie auf Stellen aus der Rechtsliteratur eingegangen; der Kurs scheint, bevor seine schriftliche Fi[71]xierung umlief, mehrmals wiederholt und im Laufe der Zeit mit Ausführungen zu Stellen aus anderen Textmassen angereichert worden zu sein. Dieser Rechtslehrer hätte also ausgeführt, was sich seine westlichen Kollegen bei ihren Theodosianus-Kursen schriftlich nur erst vorgemerkt hatten: Hic de iure addendum quid sit z. B. lex Papia. ${ }^{207}$ Kaiserkonstitutionen wurden im vorjustinianischen wie im justinianischen Rechtsunterricht an den staatlichen Rechtsschulen wie gesagt erst im fünften und letzten Studienjahr behandelt, ${ }^{208}$ weshalb all das am besten zu weit fortgeschrittenen Rechtsstudenten passt, ob sie nun auch in Antiochien volle fünf Jahre studierten oder nicht; zu einer Art Schlusskurs, ${ }^{209}$ wo der Lehrer sinnvollerweise bei passender Gelegenheit auch auf früher Gelerntes zurückkam.

\section{Die sogenannten Sententiae Syriacae}

Ähnlich überliefert wie das Syrisch-römische Rechtsbuch sind die Sententiae Syriacae, ${ }^{210}$ deren erhaltene Fassung ebenfalls auf einen vermutlich griechischen Text des späten 5. Jh. zurückgeht. Aber damals wurden offenbar nur einige wenige Aktualisierungen angebracht, während der Grundstock um 300 n. Chr. entstanden sein muss. ${ }^{211}$ Es handelt sich um präzise, sentenzenartige Wiedergaben des Hauptinhalts von Kaiserkonstitutionen; und hier lassen sich

${ }^{206}$ Selb/Kaufhold, ebd., III, S. 34 f.; u. Liebs, in: ZRG RA 121, S. 562 f. u. 567-571.

${ }^{207}$ Z. B. IT 2, 21, 2; weiteres etwa bei Liebs: Gallien (wie Anm. 7), S. 150-152; s. dazu Selb/Kaufhold, ebd., III, S. 13.

${ }^{208}$ Paul Collinet: Histoire de l'école de droit de Beyrouth, Paris 1925, S. 234-240 u. 274-279; Bernhard Kübler: Geschichte des Römischen Rechts, Leipzig 1925, S. 431; Schulz: Geschichte (wie Anm. 20), S. 351; u. Selb/Kaufhold, ebd., III, S. 34.

${ }^{209}$ Vgl. Detlef Liebs: Nachklassische römische Rechtsliteratur, in: Gerhard Thür (Hg.): Antike Rechtsgeschichte. Einheit und Vielfalt, Wien 2005, S. 27-42.

${ }^{210}$ Walter Selb: Sententiae syriacae, Wien 1990.

${ }^{211}$ Selb, ebd., S. 189-192 u. 211. 
- bedingt durch die knappere, enger an den Vorlagetexten haftende Form - diese Vorlagetexte zu mehr als drei Vierteln ermitteln: hauptsächlich Konstitutionen des Codex Hermogenianus, in größerer Zahl auch des Gregorianus und vereinzelt Paulussentenzen und jüngere Kaiserkonstitutionen. ${ }^{212}$ Am nächsten liegt wieder, dass wir einstige Summen oder indices aus Rechtsunterricht vor uns haben, ${ }^{213}$ die hier den Schülern jedoch diktiert worden waren. ${ }^{214}$ Dem entsprechenden Kurs, der zunächst um 300 gehalten, an Hand der alten Texte aber um 500 wiederaufgenommen und leicht aktualisiert worden wäre, hätten dann Auszüge aus dem Codex Hermogenianus und dem Gregorianus zugrundegelegen. Für [72] ein Praktikerkompendium ähnlich den Paulussentenzen oder vergleichbar dem Werk, aus dem wir die Fragmenta de iure fisci haben, ${ }^{215}$ war dieses Werk zu unübersichtlich. ${ }^{216}$

\section{15. Die sogenannten Scholia Sinaitica}

1879/80 entdeckte ein griechischer Gymnasialdirektor aus Mytilene im Katharinenkloster auf dem Sinai einen Einbanddeckel der Klosterbibliothek, der aus mehreren zusammengeklebten Papyrusblättern bestand, 20 Seiten hauptsächlich griechischen Text, den Rodolphe Dareste 1880 veröffentlichte. ${ }^{217} \mathrm{Um}$ den noch nicht befriedigend, vor allem bei der Abfolge der einzelnen Seiten fehlerhaft edierten Text bemühten sich alsdann Zachariae von Lingenthal und vor allem Paul Krüger. ${ }^{218} 1907$ veröffentlichte Eric O. Winstedt eine nur unvorbereitet und unter Zeitdruck möglich gewesene Revision von acht der 20 Seiten. ${ }^{219}$

Es handelt sich um ein größeres, mit Lücken durchsetztes Fragment eines umfangreichen lemmatischen Kommentars in griechischer Sprache zu Ulpians Ad Sabinum libri, also ohne diesen Grundtext, auf den durch Stichworte verwiesen ist. Der Kommentar erfasste wahr-

\footnotetext{
${ }^{212}$ Selb, ebd., S. 88-188, zusammenfassend 189-192.

${ }^{213}$ So Selb, ebd., S. 202 unten.

${ }^{214}$ Simon: Codexunterricht (wie Anm. 14), S. 335-338, bes. 336 zum Index des Thaleläus.

${ }^{215} \mathrm{Zu}$ ihnen vorläufig Detlef Liebs: Recht und Rechtsliteratur, in: Reinhart Herzog (Hg.): Handbuch der lateinischen Literatur der Antike $\overline{\bar{y}} \mathrm{~V}$ : Restauration und Erneuerung. Die lateinische Literatur von 284 bis 374 n. Chr., München 1989, S. $69=\S 507.7$.

${ }^{216}$ Siehe die ursprüngliche Gliederung des Werks, die Selb: Sententiae (wie Anm. 210), S. 203-210, zu rekonstruieren unternommen hat.

${ }^{217}$ Bulletin de la correspondance hellénique 4 (1880), S. 449-460; verbesserte Fassung: NRH 4 (1880), S. 643-657.

${ }^{218}$ Paul Krüger, Die Sinai-Scholien zu Ulpians libri ad Sabinum, in: ZRG RA 4 (1883), S. 132; seine Ausgabe für den Gebrauch im Unterricht: Collectio III (wie Anm. 120), S. 265-282.

${ }^{219}$ Classical Philology 2 (1907), S. 201-207, nach Krügers Zählung: II-IV, IX f., XV u. XVII f. Die Ausgabe von Kübler (wie Anm. 120), S. 461-484, hat seine Korrekturen berücksichtigt, wenn Kübler auch oft nicht ihnen, sondern Krüger folgt; s. a. Schulz: Geschichte (wie Anm. 20), S. 411 Anm. 2.
} 
scheinlich mindestens Buch 31 bis 41, also das Mitgift- und Vormunschaftsrecht; vermutlich aber wesentlich mehr, vielleicht sogar das ganze Werk Ulpians. ${ }^{220}$ Weitere, größ[73]tenteils unscheinbare Fragmente offenbar dieses Kommentars kamen auf einem ägyptischen Papyrus zu Tage. ${ }^{221}$

Der Kommentar tritt uns zweischichtig entgegen; dem ursprünglichen Kommentar hat ein Rechtslehrer namens $S a b$, also ein Sabinus, Sabinianus, Sabbatius, Sabucius oder Saburius ${ }^{222}$ weiter kommentierende Zusätze angefügt, die auf den ägyptischen Fragmenten noch die Form von Randscholien haben. Beide Schichten spiegeln mündlichen Rechtsunterricht ${ }^{223}$ in einer hellenistischen Provinz grob zwischen 450 und 500 n. Chr., ${ }^{224}$ wobei Beirut durchaus in Frage kommt. ${ }^{225}$ Der Unterricht war anspruchsvoll, wie schon an der Wahl des Grundtexts und der fortlaufenden Untermauerung der Erörterung mit Zitaten aus Juristenschriften und den Konstitutionencodices zu erkennen ist: öfter der Sabinuskommentar von Paulus, sodann seine Responsen, Ulpians Ediktkommentar, Marcians Ad formulam hypothecariam liber singularis, Modestins Differentiae und Regulae, sogar Florentins Institutionen, die vom Zitiergesetz ${ }^{226}$ nicht erfasst waren, und die Codices Gregorianus, Hermogenianus und Theodosianus. ${ }^{227}$

${ }^{220}$ Darauf deutet der Vermerk $\kappa \alpha$ ', also 21, am Fuß der S. 8 nach Krügers Zählung $=\S \S 16-$ 19, abgedruckt nur bei Krüger: Die Sinai-Scholien (wie Anm. 218), S. 13; er wird den laufenden Quaternio bezeichnen, dem also 20 Quaternionen vorausgegangen sein müssten. Diese sollten zumindest noch das gleichfalls im ersten Studienjahr gelehrte Testaments- (Buch 1 bis 11 besagten Kommentars) und Vermächtnisrecht (Buch 15 bis 25, s. constitutio Omnem $\S 1$ ) enthalten haben.

${ }^{221}$ Papyrus Ryland Nr. 475, hg. Colin H. Roberts: Catalogue of the Greek papyri in the John Rylands Library Manchester, III, Manchester 1938. Zum ganzen Werk s. noch Schulz: Geschichte (wie Anm. 20), S. 410-413.

${ }^{222}$ Schol. Sin. 3; 5; 9; 12; 22; 25; 30; 35; 40 f.; 44; u. 52. Die Prosopography of the later Roman Empire, II: A. D. 395-527, S. 966-70 verzeichnet 15 Sabini, sieben Sabiniani, zwei Sabbatii, einen Sabucius und einen Saburius.

${ }^{223}$ Siehe bes. Schol. Sin. 4; 26; 45 am Ende; u. 52, hier in einem Zusatz von Sab.; ferner 31; 34; 35 (Sab.); 36; 42, 44 (Sab.); 45 f.; u. 49. Auch das begeisterte ẃ $\rho \alpha$ L̃ov in $\S \S 12$ u. 27; u. Pap. Ryl. Nr. 475 (soeben Anm. 221), Frgm. b ${ }^{\mathrm{v}}$, Z. 22 des Ganzen, deutet auf mündlichen Unterricht, ebenso wie das scharfe oैं

${ }^{224}$ Einerseits ist in $\S \S 2,3(\mathrm{Sab})$ u. 52 (Sab) der Codex Theodosianus zitiert, andererseits der Codex Iustinianus noch unbekannt. Zachariae von Lingenthal, in: BIDR 5 (1893), S. 2 f., liest $\S 52$ allerdings abweichend; zustimmend Giovanni Rotondi, in: BIDR 26 (1913), S. $202=$ ders.: Scritti giuridici I, Mailand 1922, S. 139, und Liebs: Italien (wie Anm. 15), S. 136 f.; ablehnend Kübler (wie Anm. 217), S. 483. Sonst ist allenfalls in $\S 10$ (Sab) ein Kaiser genannt. Siehe a. Dieter Nörr: Zur Palingenesie der römischen Vormundschaftsgesetze, in: ZRG RA 118 (2001), S. 1-72, hier S. 13 Anm. 63.

${ }^{225}$ Provinzialen Standort verraten $\S \S 39$ u. 52 (Sab). Für Beirut vorsichtig Krüger: Geschichte (wie Anm. 20), S. 362; entschiedener dafür Collinet: Histoire (wie Anm. 208), S. 279-281.

${ }^{226}$ CTh 1, 4, 3, Teil eines umfangreichen Rechtsquellengesetzes vom 7. Nov. 426 aus Ravenna, s. Christoph Wetzler, Rechtsstaat und Absolutismus. Überlegungen zu Verfassung des 
[74] Der Verbreitung dieses zweischichtigen Kommentars lag offenbar der Text der beiden Rechtslehrer zugrunde, die in der ersten Person Singular auf frühere Ausführungen zurück- oder auch auf spätere vorausverweisen. ${ }^{228}$ Sie reden ihre Schüler in der zweiten Person Singular an; ${ }^{229}$ immer wieder fordern sie sie auf, genau bezeichnete Teile des Grundtexts zu überspringen. ${ }^{230}$

\section{Ergebnisse}

Im Allgemeinen werden im Bereich der Rechtsliteratur, insbesondere für die klassische Zeit, wie gesagt, nur exoterische Juristenschriften in Betracht gezogen, die für das große, vor allem das Fachpublikum regelrecht veröffentlicht worden waren. Doch gab es daneben offenbar zu allen Zeiten sozusagen zweitrangige Werke, die nicht jedermanns Auge sehen sollte, jedenfalls nicht von Anfang an, sondern nur ein begrenzter Kreis, insbesondere Schüler; vielfach hatte überhaupt niemand anders als der Autor den Text zu Gesicht bekommen sollen, indes geriet er dann doch in die Hände von Verehrern.

\section{1. Ältere esoterische Rechtslieratur}

Das älteste hier behandelte Beispiel für eine esoterische Juristenschrift war der Enchiridii liber singularis von Pomponius, um $130 \mathrm{n}$. Chr. anzusetzen. Damals blühte die römische Rechtsliteratur schon über 300 Jahre lang. Wenn aus der älteren, der vor- und frühklassischen Zeit kein einziger esoterischer Text einigermaßen sicher auszumachen war, so könnte dafür jedoch auch die schlechte Überlieferung der vorhadrianischen Rechtsliteratur verantwortlich

spätantiken Kaiserreichs, Berlin 1997, S. 87-108. Zur Datierung der Schrift Florentins Detlef Liebs: Römische Provinzialjurisprudenz, in: ANRW II 15, Berlin 1976, S. 288-362, hier S. 348 f.; u. Serena Querzoli: Il sapere di Fiorentino, Neapel 1996, S. 33-42. Bei Marcian ist immerhin möglich, dass sein mutmaßlicher Lehrer Ulpian ihn zitiert hatte.

${ }^{227}$ Ulpians Ediktkommentar: $\S 35$ (Sab); der Sabinuskommentar von Paulus: $\S \S 18,34$ u. 35 (Sab); seine Responsen: §§ 4 u. 31 (Sab?); Marcian: § 11 (Sab?); Modestins Differentiae: § 12 (Sab); seine Regulae: $\S 35$ (Sab); Florentin: $\S 35$ (Sab); Codex Gregorianus: $\S \S 3$ (Sab), 9 u. 10 (Sab); Codex Hermogenianus: zweimal in $\S 5$ (einmal davon Sab). In $\S 12$ (Sab) scheint nach Winstedt auch Javolen (mittelbar durch Modestin) zitiert zu sein. In $\S \S 6$ u. 8 ist der Name des Zitierten nicht mehr lesbar.

${ }^{228} \S \S 4,26$ u. (Vorausverweis) 45.

${ }^{229} \S \S 27$ a. E.; 35 gegen Anfang (Sab); u. 52 (Sab).

${ }^{230} \S \S 34 ; 43 ; 44$ (Sab); 47; u. 49. 
sein. Je weiter wir zurückgehen, um so unsicherer wird sie; repräsentative Fragmente werden immer seltener. ${ }^{231}$

[75] Aber nicht alle Literatur, die aus Rechtsunterricht hervorgegangen ist, war ursprünglich esoterisch. Vielmehr haben schon die vor- und frühklassischen römischen Juristen auch Ausbildungsliteratur veröffentlicht, beginnend mit Marcus Junius Brutus, einer der fundatores iuris civilis in der Mitte des 2. Jh. v. Chr. Noch älter waren Kommentar, Formularsammlung, geordnete Kasuistik und Monografie. ${ }^{232}$ Die Iuris civilis libri III von Brutus hatten die Form eines Dialogs mit seinem Sohn und waren publiziert. ${ }^{233}$ Quintus Mucius Skävola brachte um 100 v. Chr. Iuris civilis libri XVIII in systematischer Darstellung heraus, ${ }^{234}$ wenn wir heute an ein System auch höhere Ansprüche stellen. Masurius Sabinus publizierte im frühen 1. Jh. n. Chr. schmale Iuris civilis libri III und der Schulgründer Cassius Longinus ${ }^{235}$ kurz danach mindestens siebenmal so umfangreiche Iuris civilis libri. ${ }^{236}$ All diese Veröffentlichungen waren für den juristischen Nachwuchs konzipiert.

Für die älteste Zeit, bevor es juristische Publikationen etwa eines Gnäus Flavius gab, ist, auch wenn wir darüber keine klaren literaturhistorischen Nachrichten haben, mit esoterischer Literatur in größerem Umfang zu rechnen, mit der sogar alles angefangen zu haben scheint. Als Rechtswissen noch das Monopol bestimmter Priesterschaften war, ${ }^{237}$ gab es interne Aufzeichnungen etwa der pontifices, ${ }^{238}$ wohl auch der Auguren für staatsrechtliche und der Fetialen für völkerrechtliche Akte. Von Coruncanius, pontifex und 253 v. Chr. erster plebejischer

${ }^{231}$ Eine vollständige Sammlung alles Überlieferten, insoweit wesentlich reicher als Otto Lenel in seiner Palingenesia (wie Anm. 19), der zur vorhadrianischen Rechtsliteratur hauptsächlich die Digesten ausgewertet hat, bietet Franz Peter Bremer: Iurisprudentiae antehadrianae quae supersunt, 3 Bde.: I, Leipzig 1896; II 1, 1898; u. II 2, 1901; knapper Seckel/Kübler (wie Anm. 135), S. 1-93.

${ }^{232}$ Überblick bei Detlef Liebs: Archaische Rechtsbücher, in: Handbuch I (wie Anm. 28), S. $75-9=\S 111$; zur Monografie De usurpationibus von Appius Claudius Caecus um 300 v. Chr. zurückhaltend Suerbaum, ebd., S. $83=\S 112$ W. 4.

${ }^{233}$ Zusammenfassend dazu Liebs: Die vorklassischen juristischen Fachschriften, in: Handbuch I (wie Anm. 28), S. 565 f. $=\S$ 194.6; zum Autor und zum Adressaten ferner ders.: Die Juristensippe der Marci Junii Bruti, in: Festschrift für Peter Schlechtriem zum 70. Geburtstag, Tübingen 2003, S. 107-117.

${ }^{234}$ Pomponius D. 1, 2, $2 \S 41:$ Q. Mucius ... ius civile primus constituit generatim in libros decem et octo redigendo. Dazu Liebs: Die vorklassischen (wie Anm. 23z̧ㅡ), S. 570 f. $=\S$ 195.1 W. 2.

${ }^{235}$ Liebs: Rechtsschulen (wie Anm. 35), S. 198-209.

${ }^{236} \mathrm{Zu}$ ihnen und zum Werk des Sabinus demnächst Detlef Liebs: Recht und Jurisprudenz, in: Peter Lebrecht Schmidt (Hg.): Handbuch der lateinischen Literatur der Antike III (erscheint ca. 2010), § 326.1 f. W. 4 u. W. 1.

${ }^{237}$ Siehe Pomponius D. $1,2,2 \S 35$.

${ }^{238}$ Die commentarii pontificum, dazu Gerhard Radke, in: Handbuch I (wie Anm. 28), S. $59=$ $\S 108.1$; u. Hubert u. Astrid Petersmann, ebd., S. 63 f. $=\S 108.5$. 
pontifex maximus, der erstmals das Recht öffentlich lehrte, berichtet Pomponius: cuius tamen scriptum nullum exstat, sed responsa complura et memorabilia eius fuerunt - von ihm gibt es allerdings keine einzige Schrift, aber etliche bemerkenswerte Responsen liefen [76] um. Daraus hat man auf eine Responsensammlung geschlossen, ${ }^{239}$ aber das war Wunschdenken, genährt von der Anschauung der spätklassischen Responsensammlungen eines Cervidius Skävola, Papinian, Paulus oder Modestin. Ein Literaturwerk wird von Pomponius ausdrücklich verneint; die Rede ist lediglich von etlichen bemerkenswerten Responsen. Cicero und Plinius d. Ä. berichten von einzelnen Responsen des Coruncanius; ${ }^{240}$ sie müssen also aufgezeichnet gewesen sein, ohne dass wir mit einer regelrechten Veröffentlichung durch den Autor oder Schüler rechnen dürfen. Pomponius gebraucht hier nicht das Wort liber, libri, das er bei Vorstellung der Werke von Appius Claudius, Gnäus Flavius und Sextus Älius verwendet. ${ }^{241}$ Vermutlich handelte es sich bei Coruncanius um esoterisches Schulgut, wenn sich dazu auch keine bestimmte Aussage machen lässt. Auf ähnliche Weise könnte Servius zuverlässige Kunde von den Responsen der Zwischengeneration zwischen Quintus Mucius Skävola und ihm gehabt haben: von den Gutachten der nichtliterarischen Juristen Gajus Aquilius Gallus, Lucius Lucilius Balbus (seine Lehrer), Sextus Papirius und Titus Iuventius. ${ }^{242}$ Vielleicht lassen sich auch die unsicheren drei libri des Sextus Älius ${ }^{243}$ auf diese Weise erklären.

\section{Die Autoren der esoterischen Literatur}

26 Werke wurden behandelt, woraus man auf den ersten Blick auf 26 verschienene Autoren schließen würde, doch waren jedenfalls bei zwei Texten, den Sententiae Syriacae und den Sinaischolien, mehrere Autoren am Werk; zumindest diese Werke sind mehrschichtig. Umgekehrt ist nicht auszuschließen, dass zwei oder auch mehr der behandelten Werke vom selben Autor stammen. ${ }^{244}$ In acht Fällen war der Autor wenigstens dem Namen nach bekannt: Pom-

239 Siehe etwa Schulz: Geschichte (wie Anm. 20), S. 107-109; Gerhard Dulckeit/Fritz Schwarz/Wolfgang Waldstein, Römische Rechtsgeschichte, 7. Aufl., München 1981, S. 152. Ablehnend demgegenüber Detlef Liebs, Römische Rechtsgutachten und Responsorum libri, in: G. Vogt-Spira (Hg.): Strukturen der Mündlichkeit in der römischen Literatur, Tübingen 1990, S. $84 \mathrm{f}$.

${ }^{240}$ Cicero, De legibus 2, 52; u. Plinius, Naturalis historia 8, 206.

${ }^{241}$ Pomponius D. 1, 2, $2 \S \S 7,36$ u. 38.

${ }^{242}$ Siehe Pomponius D. 1, 2, $2 \S 42 . \mathrm{Zu}$ ihnen Kunkel: Herkunft (wie Anm. 73), S. 21-23= Nr. 34-37.

${ }^{243}$ Pomponius, aaO $\S 38 . \mathrm{Zu}$ ihm Liebs: Archaische (wie Anm. 232), S. 78 f. $=\S 111.4$.

${ }^{244}$ Vgl. die Identifizierung der Autoren zweier frühmittelalterlicher Summen, nämlich der Summa Perusina zum Codex Iustinianus und der jüngeren Kapitelsummarien zur Epitome 
ponius, Julian, Mäcian, Gajus, ein sonst unbekannter [77] Skävola, Paulus und die späten Oströmer Ambrosius und Sab., und bis auf diese beiden gehörten alle der klassischen Zeit an. Von dem hier behandelten Skävola kennen wir allerdings nur die Fragmente seines hier behandelten Werks und sein ruhmrediges Cognomen; auch von Ambrosius nur dieses beides und bei Sab. vom Namen gar nur die ersten drei Buchstaben. Nicht von diesen dreien, aber von den übrigen fünf kennen wir dagegen zahlreiche andere, exoterische Werke; sie gehören zu den Klassikern.

Von den verbleibenden 18 Werken, drei davon aus klassischer Zeit, ${ }^{245}$ ist der Autor völlig unbekannt, weshalb auch ein Autorenkollektiv in Betracht kommt.

\section{Der Entstehungszusammenhang}

Betrachten wir nun die Umstände, die zur Entstehung der esoterischen Werke geführt haben, so wird zunächst einmal niemanden überraschen, dass fast alle, wie meist mit großer Sicherheit gesagt, im Übrigen vermutet werden konnte, aus Rechtsunterricht hervorgegangen sind. Sechsmal war es Anfängerunterricht ${ }^{246}$ und 18mal Unterricht für Fortgeschrittene, darunter achtmal an Hand der Kaiserkonstitutionen, ${ }^{247}$ die am Ende des Studiums behandelt wurden. Eine einzige kleine Gelegenheitsarbeit diente wahrscheinlich dem behördeninternen Gebrauch. ${ }^{248}$ Als Rahmen des Unterrichts war viermal eine der beiden bekannten römischen Rechtsschulen wahrscheinlich ${ }^{249}$ und ein fünftes Mal nicht auszuschließen. ${ }^{250}$ Einmal war ein angesehener Klassiker als Privatlehrer in Rom für privatissime erteilten Unterricht bezeugt. ${ }^{251}$ Aber auch Unterricht bei einem Privatlehrer in Italien, der durchaus „öffentlich“ (publice)

Iuliani durch Wolfgang Kaiser, Die Epitome Iuliani, Frankfurt am Main 2004, S. 341-346 u. 380.

${ }^{245}$ Beim Fragmentum Dositheanum (oben unter II. 3.), bei Pseudoulpians Regularum liber singularis (oben I. 2.) und beim Stemma agnationis (oben III. 3.).

${ }^{246}$ Beim Enchiridii liber singularis von Pomponius, dem Fragmentum Dositheanum, den gajanischen Institutionen, Pseudoulpians Regularum liber singularis, dem Gajus von Autun und der Gajusepitome.

${ }^{247}$ Bei den Interpretationen zu den Codices Gregorianus und Hermogenianus, den Sententiae Syriacae, etwa drei Apparaten zum Theodosianus samt Novellen und dem Syrisch-römischen Rechtsbuch.

${ }^{248}$ Anonymus De gradibus.

${ }^{249}$ Bei Pomponius und Julian die cassianische und bei Pseudoulpian und wohl auch Paulus die prokulianische.

${ }^{250}$ Bei Skävolas Quaestiones publice tractatae die sabinianische; ihr war bekanntlich auch Gajus verbunden.

${ }^{251}$ Mäcian als Rechtslehrer des Kronprinzen Mark Aurel. 
stattfinden konnte, kam in Betracht. ${ }^{252}$ In der Spätantike schließlich war in 14 Fällen Rechtsunterricht in der Provinz sicher oder doch am wahrscheinlichsten, vermutlich bei einem privaten [78] Rechtslehrer: zehnmal im Westen ${ }^{253}$ und dreimal im Osten; ${ }^{254}$ einmal war das nicht zu entscheiden. ${ }^{255}$ In zwei weiteren Fällen schien die öffentliche Rechtsschule von Beirut grob zwischen 450 und 500 nicht unwahrscheinlich. ${ }^{256}$ Unterrichtssprache war meist lateinisch, in vier späten Fällen griechisch, ${ }^{257}$ von Justinian an wird diese Sprache ganz überwiegen.

\section{Der Weg in die schriftliche Überlieferung}

Versuchen wir nun, uns zu vergegenwärtigen, wie die einzelnen Texte zu ihrer heute sichtbaren schriftlichen Form gelangten und in die Überlieferung eingingen. Konkrete Anhaltspunkte dazu waren selten, doch legte die Art der Texte immer wieder Vermutungen nahe, denen nun im Zusammenhang nachzugehen ist, bei aller Unsicherheit, die hier zurückbleiben muss. Dass mitstenografiert und dann von Schülerhand redigiert wurde, mit dieser Arbeitshypothese sind Wendungen im Kolloquialstil in sieben Werken am besten zu erklären, vier aus klassischer ${ }^{258}$ und drei aus nachklassischer Zeit. ${ }^{259}$ Ein Werk war am besten als fehlerhaft redigierte Mitschrift $\mathrm{zu}$ deuten. ${ }^{260}$ Bei den meisten Interpretationen und den syrischen Texten, zusammen zehn Werke, lag ein vom Lehrer ausformulierter und diktierter ${ }^{261}$ oder ein schriftlich vom Lehrer bezogener $\mathrm{Text}^{262}$ am nächsten, was außerdem bei sechs weiteren Werken vermutet werden konnte; ${ }^{263}$ nicht alles kann hier eingeordnet werden.

${ }^{252}$ Bei Skävola, s. aber soeben Anm. 250.

${ }^{253}$ Gajus von Autun, Gajusepitome, Antiqua Summaria zum Theodosianus, die Interpretationenapparate zum Codex Gregorianus, Hermogenianus, mindestens zwei zu den Paulussentenzen und drei zum Theodosianus.

${ }^{254}$ Gajus, die Sententiae Syriacae und das Syrisch-römische Rechtsbuch.

${ }^{255}$ Beim Fragmentum Dositheanum, wo überdies auch Italien als Unterrichtsort in Betracht kommt.

${ }^{256}$ Bei beiden Schichten der Sinaischolien.

${ }^{257}$ Sententiae Syriacae, Syrisch-römisches Rechtsbuch und beide Schichten der Sinaischolien.

${ }^{258}$ Julian, De ambiguitatibus; die gajanischen Institutionen; Skävola, Quaestiones publice tractatae; und Paulus, Manualia.

${ }^{259}$ Gajus von Autun, Sinaischolien und Sab. dort.

${ }^{260}$ Der Enchiridii liber singularis von Pomponius.

${ }^{261}$ Jedenfalls bei den Sententiae Syriacae und dem Syrisch-römischen Rechtsbuch, wohl auch bei den Interpretationen zum Gregorianus und Hermogenianus.

${ }^{262}$ Dies bei der Gajusepitome und den Interpretationen zum Theodosianus mitsamt Novellen.

${ }^{263}$ Bei Mäcians Distributio assis, Pseudo-Ulpian, den Stemmata agnationis und cognationum, dem Anonymus De gradibus und den Antiqua summaria zum Theodosianus. 
[79] Die bei den exoterischen Schriften bis weit ins 3. Jh. übliche Unterteilung in libri ${ }^{264}$ ist bei unseren esoterischen Texten nur in zwei Fällen aus hoch- und spätklassischer Zeit zu beobachten, ${ }^{265}$ als die Verbreitung von Werken ohne dieses Element noch undenkbar schien; andere esoterische Werke aus dieser Zeit firmierten in der späteren Überlieferung als libri singulares, doch ist in all diesen Fällen ungewiss, ob der Umfang wirklich nur den einer einzigen Buchrolle des üblichen Umfangs hatte. ${ }^{266}$ Auch bei den Buchtiteln wird man, soweit solche überhaupt überliefert sind, öfter zweifeln, ob sie vom Autor stammen oder von den die Werke in Umlauf setzenden Schülern und sonstigen Verehrern, insbesondere dann, wenn der Autor das unautorisiert umlaufende Werk durch ein gründlich ausgearbeitetes zu ersetzen versucht und dabei einen anderen Titel gewählt hat. ${ }^{267}$ Mitunter verleugnete der Index Florentinus die unautorisierte Erstausgabe, obwohl sie in den Digesten ausgiebig benutzt wurde. ${ }^{268}$ Am Ende liefen viele dieser esoterischen Texte wie ein reguläres Literaturwerk um.

Esoterische Rechtsliteratur beherrschte in den folgenden Jahrhunderten das Feld, wie es ja auch in der ältesten Zeit zunächst nur esoterisches juristisches Schrifttum gab. Aber auch die klassische Zeit hindurch wurde die hochgeschätzte klassische Rechtsliteratur von esoterischer begleitet, deren einstiges Ausmaß schwer einzuschätzen ist. Vielleicht muss man sogar sagen, dass in Zeiten handschriftlicher Vervielfältigung esoterische Literatur normal war und regelrechte Publikationen die aufwendige Ausnahme; oft, wenn es nämlich ehrgeizige Verehrer gab, war eine Publikation aber auch das schließliche Schicksal esoterischer Werke. In den letzten 550 Jahren, als der Buchdruck den Medienmarkt beherrschte, war die Trennung schärfer und hatte esoterische Literatur, die es an den Schulen, Universitäten und in sonstigen engeren Zirkeln immer gab, nur untergeordnete Bedeutung. Aber das Internet lässt die esoterische Literatur wieder blühen; und hier verschwimmen die Unterschiede, denn im Internet wird auch exoterische Literatur angeboten.

${ }^{264}$ Nicht mehr bei den Responsa von Julius (Gallus?) Aquila, s. Liebs: Jurisprudenz (wie Anm. 10), S. 126 f. $=\S 417.4$, dem Codex Hermogenianus und den Fragmenta Vaticana.

${ }^{265}$ Den gajanischen Institutionen und Pauls Manualia.

${ }^{266}$ Insbesondere bei Pseudo-Ulpian, s. dazu Avenarius: Der pseudo-iulpianische liber (wie Anm. 6), S. 145 f. Ferner beim Enchiridii liber singularis von Pomponius, Julians De ambiguitatibus liber singularis und Skävolas Quaestionum publice tractatarum liber singularis.

${ }^{267}$ Das tat meines Erachtens Gajus mit den Res cottidianae, wenn er auch bei der esoterischen Fassung mit Institutiones einverstanden gewesen sein mag. Unsicher ist auch, inwieweit Julian für den der Rhetorik verpflichteten Titel De ambiguitatibus und Paulus für den werbenden Titel Manualia verantwortlich waren.

${ }^{268}$ So beim Enchiridii liber singularis von Pomponius. 


\section{Abkürzungen}

ANRW = Hildegard Temporini (Hg.): Aufstieg und Niedergang der römischen Welt, Berlin $1972 \mathrm{ff}$.

BIDR $=$ Bullettino dell'Istituto di Diritto Romano, Mailand

$\mathrm{CIL}=$ Corpus inscriptionum Latinarum, Berlin $1862 \mathrm{ff}$.

$\mathrm{CJ}=$ Codex Iustinianus

CLA = Elias A. Lowe (Hg.): Codices Latini antiquiores, Oxford 1934-1972

$\mathrm{CTh}=$ Codex Theodosianus

D. = Digesta Iustiniani

FIRA = Fontes iuris Romani antejustiniani, 2. Aufl., 3 Bde., Florenz 1940-1943

$\mathrm{GE}=$ Gai Epitome der Lex Romana Visigothorum

$\mathrm{IH}=$ Interpretationen zum Codex Hermogenianus

ILS = Hermann Dessau (Hg.): Inscriptiones Latinae selectae, Berlin 1892-1926

$\mathrm{IP}=$ Interpretationen zu Pseudo-Paulus, Sentenzen

IT = Interpretationes zum Codex Theodosianus

$\mathrm{NRH}=$ Nouvelle revue historique de droit français et étranger, Paris

$\mathrm{PM}=$ Paulus, Manualia

PS $=$ Pseudo-Paulus, Sentenzen

$\mathrm{RE}=$ Georg Wissowa u. a. (Hg.): Paulys Realencyclopädie der classischen Altertumswissenschaft. Neue Bearbeitung, Stuttgart 1893-1980

$\mathrm{RH}=$ Revue historique de droit français et étranger

RIDA $=$ Revue internationale des droits de l'antiquité, 3. Serie, Brüssel

RJ $=$ Rechtshistorisches Journal, Frankfurt am Main 1982-2001

ThLL $=$ Thesaurus linguae Latinae, Leipzig $1900 \mathrm{ff}$.

VIR = Vocabularium iurisprudentiae Romanae, Berlin 1894-1987

ZRG RA = Zeitschrift der Savigny-Stiftung für Rechtsgschichte. Romanistische Abteilung 